This item was submitted to Loughborough's Research Repository by the author.

Items in Figshare are protected by copyright, with all rights reserved, unless otherwise indicated.

\title{
Influence of variable valve timings on the gas exchange process in a controlled auto-ignition engine
}

PLEASE CITE THE PUBLISHED VERSION

\section{PUBLISHER}

(C) IMechE / Professional Engineering Publishing

\section{VERSION}

VoR (Version of Record)

\section{LICENCE}

CC BY-NC-ND 4.0

\section{REPOSITORY RECORD}

Milovanovic, Nesa, Rui Chen, and J.W.G. Turner. 2009. "Influence of Variable Valve Timings on the Gas Exchange Process in a Controlled Auto-ignition Engine”. figshare. https://hdl.handle.net/2134/4501. 
This item was submitted to Loughborough's Institutional Repository (https://dspace.lboro.ac.uk/) by the author and is made available under the following Creative Commons Licence conditions.

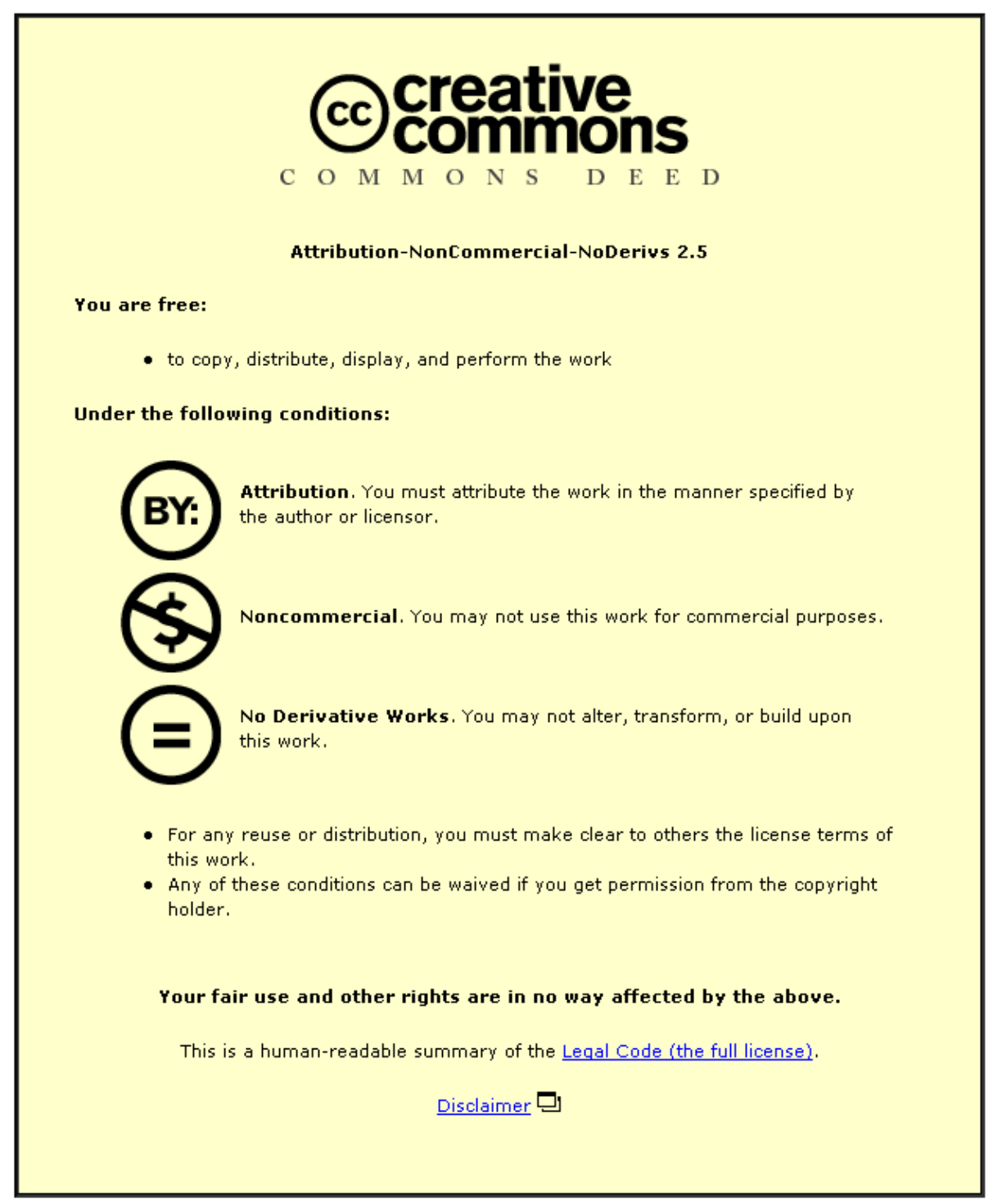

For the full text of this licence, please go to: http://creativecommons.org/licenses/by-nc-nd/2.5/ 


\title{
Influence of variable valve timings on the gas exchange process in a controlled auto-ignition engine
}

\author{
$\mathbf{N}$ Milovanovic $^{1 *}, \mathbf{R} \mathbf{C h e n}^{1}$ and $\mathbf{J}$ Turner $^{2}$ \\ ${ }^{1}$ Aeronautical and Automotive Department, Loughborough University, Loughborough, UK \\ ${ }^{2}$ Powertrain Research Department, Lotus Engineering, UK
}

\begin{abstract}
The controlled auto-ignition (CAI) engine concept has the potential to be highly efficient and to produce low $\mathrm{NO}_{x}$ and particulate matter emissions. However, the problem of controlling the combustion over the entire load/speed range limits its practical application. The CAI combustion is controlled by the chemical kinetics of the charge mixture, with no influence of the flame diffusion or turbulent propagation. Therefore, to achieve successful control of the CAI process, the composition, temperature and pressure of the charge mixture at the inlet valve closure (IC) point have to be controlled. The use of the variable valve timing strategy, which enables quick changes in the amount of trapped hot exchaust gases, shows the potential for control of CAI combustion. The aim of this paper is to analyse the influence of the variable valve timing strategy on the gas exchange process, the process between the first valve open event (EO) and the last valve closing event (IC), in a CAI engine fuelled with standard gasoline fuel $(95 \mathrm{RON})$. The gas exchange process affects the engine parameters and charge properties and therefore plays a crucial role in determining the control of the CAI process. Analysis is performed by experimental and modelling approaches. A single-cylinder research engine equipped with a fully variable valvetrain (FVVT) system was used for the experimental study. A combined code consisting of a detailed chemical kinetics code and one-dimensional fluid dynamics code was used for the modelling study. The results obtained indicate that the variable valve timing strategy has a strong influence on the gas exchange process, which in turn influences the engine parameters and the cylinder charge properties, and hence the control of the CAI process. The EC timing has the strongest effect, followed by the IO timing, while the EO and IC timings have minor effects.
\end{abstract}

Keywords: controlled auto-ignition, control, variable valve timing, gas exchange process, internal exhaust gas recirculation, gasoline

\begin{tabular}{|c|c|}
\hline $\mathrm{ABDC}$ & after bottom dead centre \\
\hline ATDC & after top dead centre \\
\hline ATDC $_{\text {overlap }}$ & $\begin{array}{l}\text { after top dead centre overlap } \\
\text { (gas exchange process) }\end{array}$ \\
\hline AVT & active valve train \\
\hline b.m.e.p. & break mean effective pressure \\
\hline b.s.f.c. & break specific fuel consumption \\
\hline $\mathrm{BDC}$ & bottom dead centre \\
\hline BTDC $_{\text {overlap }}$ & $\begin{array}{l}\text { before top dead centre overlap } \\
\text { (gas exchange process) }\end{array}$ \\
\hline $\mathrm{CA}$ & crank angle \\
\hline
\end{tabular}

The MS was received on 13 August 2003 and was accepted after revision for publication on 30 January 2004.

* Corresponding author: Aeronautical and Automotive Engineering Department, Loughborough University, Loughborough, Leicester, LE11 $3 T U, U K$.

EC
EO
FVVT
GEP
i.m.e.p. (PMI)
IC
IEGR
IO
MOP
$n$
RON
TDC
TDC $_{\text {comb }}$

$\varepsilon \quad$ compression ratio

$\varphi_{\mathrm{EC}}$

$\varphi_{\text {EO }}$

$\varphi_{\mathrm{IC}}$

$\varphi_{\mathrm{IO}}$ exhaust valve closure

exhaust valve open

fully variable valvetrain

gas exchange process

indicated mean effective pressure

inlet valve closure

internal exhaust gas recirculation

inlet valve open

maximum open point (valve)

revolutions per minute

research octane number

top dead centre

top dead centre combustion

exhaust valve closure timing $\left({ }^{\circ} \mathrm{C}\right)$

exhaust valve open timing $\left({ }^{\circ} \mathrm{C}\right)$

inlet valve closure timing $\left({ }^{\circ} \mathrm{C}\right)$

inlet valve open timing $\left({ }^{\circ} \mathrm{C}\right)$ 


\section{INTRODUCTION}

Controlled autoignition (CAI) combustion is a process that combines features of the spark ignition (SI) and compression ignition $(\mathrm{CI})$ processes. In a CAI engine the air and fuel are premixed homogeneously prior to ignition and then ignited by the compression from the piston motion. The ignition is provided at multiple points and therefore the charge gives a parallel energy release. This results in uniform and simultaneous autoignition and chemical reaction throughout the whole charge without flame propagation. In CAI combustion the chemical kinetics of the air-fuel mixture plays a crucial role, with no requirements for turbulence and mixing.

Controlled autoignition combustion was initially recognized in two-stroke engines in the late 1970s by Onishi et al. [1] and Noguchi et al. [2]. They observed that the premixed air-fuel mixture ignited simultaneously at many points without obvious flame propagation. The notion that CAI combustion is dominated by the chemical kinetics of the air-fuel mixture employed has been supported by recent spectroscopic and imaging investigations $[3,4]$. The results obtained indicate that the ignition occurs simultaneously at multiple points with no flame propagation.

The CAI engine offers benefits in comparison with the spark ignition and compression ignition engines: higher efficiency due to elimination of throttling losses at part and idle loads; the possibility of using high compression ratios since it is not knock limited; significantly lower $\mathrm{NO}_{x}$ and particulate matter emissions owing to a much lower combustion temperature and the elimination of fuel-rich zones. Furthermore, the CAI engine has the advantage of fuel flexibility. Since CAI combustion is not constrained by knock, as in the SI combustion, a wide range of fuels can be used.

The disadvantages of the CAI engine are the relatively high hydrocarbon and carbon monoxide emissions at low loads, the high peak pressures and rates of heat release at high loads, the reduced engine speed range and power per displacement and difficulties in starting and controlling the engine. Some of these disadvantages may be reduced or eliminated by operating the CAI engine in a 'hybrid mode', or by using different types of catalytic converter. However, there are some problems regarding the control of a CAI engine over the entire load/speed range that keep the CAI out of commercial use.

The control of CAI combustion consists of two aspects: the control of the ignition timing occurring in the vicinity of top dead centre (TDC) and the control of the heat release rate (combustion speed) at high loads to prevent excessive noise and engine damage. Controlled autoignition is determined by the charge mixture temperature and composition and, to a lesser extent, pressure. In this way, CAI combustion is achieved by controlling the charge mixture temperature, composition and pressure (i.e. charge mixture properties) at the beginning of the compression stroke [the inlet valve closure (IC) point]. As CAI combustion is kinetically controlled, the rate of heat release depends on correct combustion phasing and is closely linked with the ignition delay. Therefore, a successful control strategy has to be able to control the charge mixture properties at the IC point over the entire load/speed range.

Different methods that have the potential to control the start of autoignition and the heat release rate of CAI combustion, together with their effectiveness and practical feasibility, have been discussed in reference [5]. Internal exhaust gas recirculation (IEGR), i.e. trapping the hot exhaust gases into the cylinder, accomplished by a fully variable valvetrain (FVVT) system, appears to be the most promising and the most feasible way of achieving CAI combustion control in a certain load range [6]. The FVVT system allows quick changes in the cylinder charge temperature and composition by retaining the hot exhaust gases from previous cycles. By varying the amount of hot exhaust gases, the temperature and composition of the charge mixture can be adjusted.

The aim of this paper is to analyse the influence of the variable valve timing strategy on the gas exchange process (GEP) in a CAI engine fuelled with standard gasoline fuel (95RON). The GEP takes place between the first valve open event (EO) and the last valve closing event (IC). Since the GEP precedes the compression stroke, where the autoignition and heat release processes occur, it influences the engine parameters and charge mixture properties, and hence the control of CAI combustion.

Analysis was performed by experimental and modelling approaches. A single-cylinder research engine equipped with a fully variable valvetrain (FVVT) system was used for the experimental study. A combined code consisting of a detailed chemical kinetics code and one-dimensional fluid dynamics code was used for the modelling study.

The effects of the variable valve timing strategy on the engine parameters (such as the IEGR rate, load, pumping losses, volumetric efficiency and trapped gas temperature) and cylinder charge properties (such as composition, temperature and pressure) were investigated.

\section{EXPERIMENTAL APPARATUS AND SET-UP}

\subsection{Engine}

The engine employed in this research is a single-cylinder, four-stroke research engine based on the GM Family One 1.81 series architecture. A photograph of the engine is shown in Fig. 1.

It consists of a production piston, connecting rod and stroke, with a standard four-cylinder head on top of a water-cooled barrel to join the Family One part to 


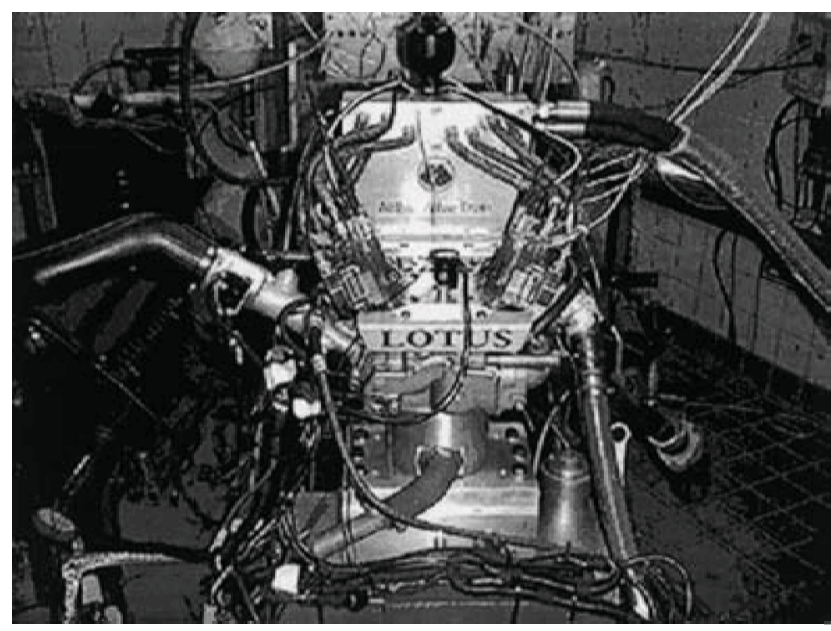

Fig. 1 Single-cylinder research engine with the Lotus AVT system

the custom-made bottom end. Only the front cylinder of the head is operational. The water jacket uses a combination of machined modifications and brackets. Unnecessary water transfer ports are blanked off. The engine has a bespoke single-cylinder bottom end designed and developed by Lotus to allow either pure combustion work or optical access versions to be built. The exhaust system used on the single-cylinder research engine was a standard one. The system was not modified since the exhaust gases were trapped into the cylinder by using the early exhaust valve closure event coupled with the late inlet valve opening event. In this way, a major amount of available IEGR was trapped inside the cylinder (up to 80 per cent) and the rest was discharged through the exhaust system.

The major engine specifications and test conditions are shown in Table 1. A detailed description of the engine can be found in reference [6].

The research FVVT system is fitted to allow the variable valve timing strategy to be used to trap the predefined quantity of IEGR. The open and closing timings of each of four electrohydraulically driven valves

Table 1 Single-cylinder engine specification and test conditions

\begin{tabular}{ll}
\hline Bore & $80.5 \mathrm{~mm}$ \\
Stroke & $88.2 \mathrm{~mm}$ \\
Swept volume & $450 \mathrm{~cm}^{3}$ \\
Compression ratio & 10.5 \\
Speed & $\leqslant 5000 \mathrm{r} / \mathrm{min}$ \\
Load range & $2-5$ bar (i.m.e.p.) \\
Number of valves per cylinder & 4 \\
Valve control & Electrohydraulic \\
& Lotus AVT-FVVT system \\
Fuel injection & Port fuelled \\
Fuel & Gasoline (95RON) \\
Equivalence air-fuel ratio & Stoichiometric \\
Intake temperature & $25^{\circ} \mathrm{C}$ \\
Inlet pressure & Naturally aspirated \\
IEGR & $\leqslant 80$ vol\% \\
\hline
\end{tabular}

D14403 (C) IMechE 2004 are independent variables and can be digitally controlled. Valve opening profiles can be selected and entered into the software by the user. The control software uses inputs from a crankcase encoder and valve linear displacement transducers to facilitate a closed-loop control to satisfy a 'desired versus actual' position control until the required profiles are achieved. Fine tuning of valve profiles is accomplished by using valve-specific gain controllers.

The engine was connected to a Froude AG30, $30 \mathrm{~kW}$ eddy-current dynamometer. A redline ACAP data acquisition system from DSP Technologies Incorporated is used, together with a Horiba MEXA 7100 DEGR emissions analyser. The fuel was port injected and the engine management system was a conventional Lotus V8 controller.

\subsection{Valve events for CAI combustion}

The technique used to initiate and to control CAI combustion relies on the trapping of a predetermined quantity of exhaust gases by closing the exhaust valves relatively early in the exhaust stroke and by opening the inlet valves relatively late in the intake stroke. The general principle can be seen in Fig. 2a.

The trapped exhaust gases are then compressed during the final stage of the exhaust stroke. As the piston descends on the intake stroke, the inlet valves are opened and a fresh charge is drawn into the cylinder which is partially filled with exhaust gases. At the end of the intake stroke the inlet valves are closed and the mixture of fresh charge and exhaust gas is then compressed in the next compression stroke. The CAI combustion occurs as the mixture temperature increases in the final stage of the compression stroke. Once CAI has occurred, the power stroke drives the piston down and the cycle is thus repeated. This is the sequential method. Another method for achieving CAI combustion, the simultaneous method, has also been derived, and detailed explanations can be found in references [6] and [7].

In order to trap the various quantities of IEGR and to obtain transition from conventional SI combustion to CAI combustion, series of valve timings are used. Figure $2 \mathrm{~b}$ summarizes the valve timings and estimated quantities of trapped IEGR.

Transition from SI to CAI mode is achieved by increasing the negative valve overlap between the exhaust valve closure event, $\varphi_{\mathrm{EC}}$, and inlet valve opening event, $\varphi_{\mathrm{IO}}$, and by reducing the valve lift. The intake and exhaust valve events are varied from a 'normal' valve event with positive valve overlap (as for a typical fourstroke SI engine) to a very early $\varphi_{\mathrm{EC}}$ coupled with a symmetrically very late $\varphi_{\mathrm{IO}}$. With increase in the negative valve overlap, a camless CAI engine goes from conventional SI operation, through a transient period and into CAI operation $[\mathbf{6}, \mathbf{8}]$. Valve lifts of $8 \mathrm{~mm}$ for the exhaust valves and $8.5 \mathrm{~mm}$ for the inlet valves are used for the SI mode. When the engine is operated in a transient 


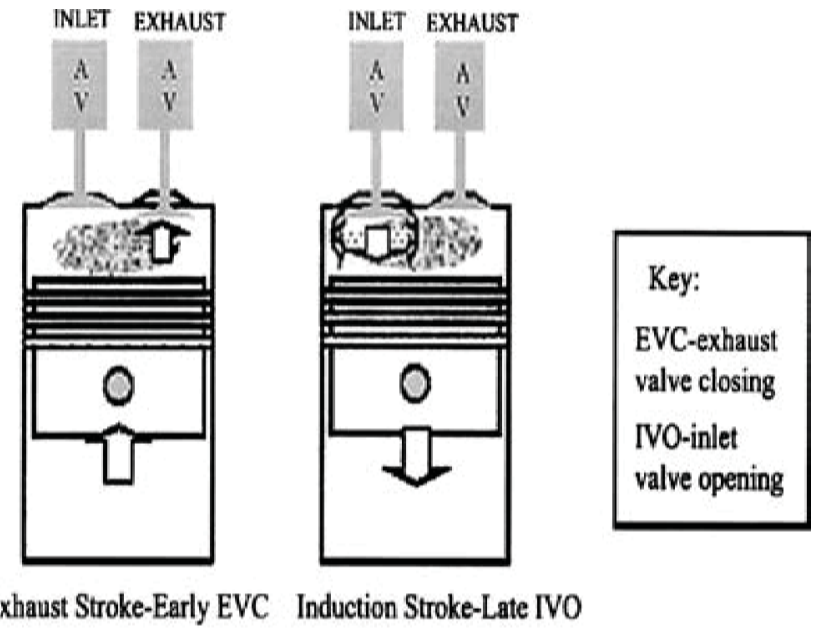

(a)

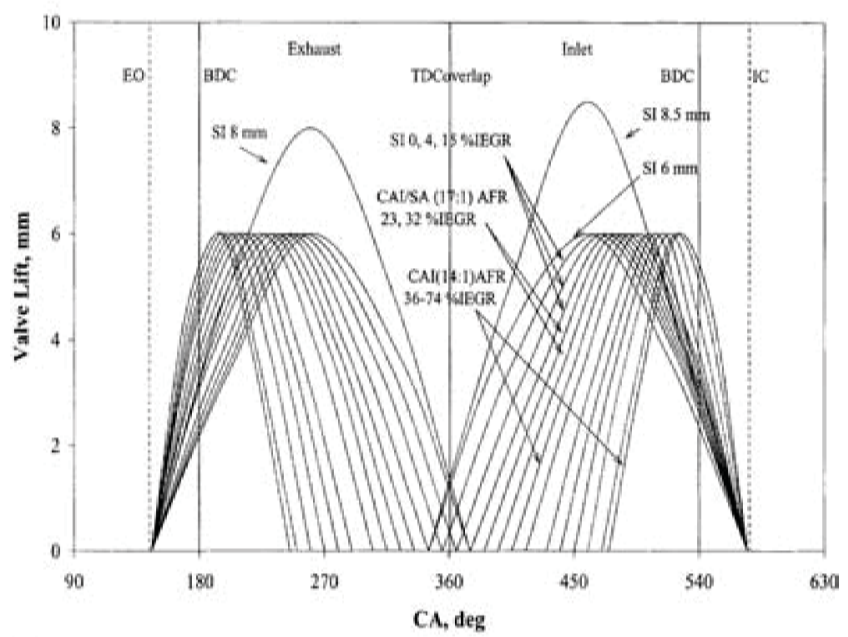

(b)

Fig. 2 (a) Sequential valve event strategy and (b) conventional valve profiles for SI combustion and profiles suitable for CAI combustion

and in CAI mode, the valve lift is reduced to $6 \mathrm{~mm}$ for all valves (exhaust and intake). The reduction in valve lift is applied to reduce the valve dynamic loading to an acceptable level.

The $\varphi_{\mathrm{EC}}$ is varied from 245 to $375^{\circ}$ crank angle (CA) absolute scale, as shown in Fig. 2b. The absolute scale has $0^{\circ} \mathrm{CA}$ when the piston is in the TDC of the combustion cycle $\left(\mathrm{TDC}_{\mathrm{comb}}\right)$.

The $\varphi_{\mathrm{IO}}$ is varied symmetrically relative to $\mathrm{TDC}_{\text {overlap }}$ ( $\mathrm{TDC}_{\text {overlap }}$ is when the piston is in the TDC of the expansion cycle or $\left.360^{\circ} \mathrm{CA}\right)$. When the distance from $\varphi_{\mathrm{EC}}$ to the $\mathrm{TDC}_{\text {overlap }}$ is equal to the distance from $\mathrm{TDC}_{\text {overlap }}$ to the $\varphi_{\mathrm{IO}}$, measured in degrees CA, the valve overlap, positive or negative, is symmetrical. When the valve overlap is symmetrical, the cylinder pressure at the IO is approximately the same as that at the EC. This allows maximum recovery of the available compression work with the minimum reverse flow of exhaust gases into the intake manifold [7-9].
The $\varphi_{\mathrm{EO}}$ and $\varphi_{\mathrm{IC}}$ timings are kept constant at 145 and $575^{\circ} \mathrm{CA}$ respectively. Other engine parameters such as the compression ratio, engine speed, intake temperature and equivalence air-fuel ratio are kept constant at the values specified in Table 1.

\section{SIMULATION MODEL}

The simulation of the CAI engine is carried out by combining the Aurora detailed chemical kinetics code from the Chemkin III combustion package [10] with the one-dimensional fluid-dynamic Lotus engine simulation (LES) code [11].

The Aurora code considers the engine chamber as a single-zone reactor of variable volume. The volume is varied with time according to the slider-crank relationship. The mixture of fuel, air and exhaust gases is assumed to be homogeneous, with even spatial distribution of mixture composition and thermodynamic properties. The heat loss is calculated by using Woschni's heat transfer correlation with a temperature difference between the average gas temperature and the timeaveraged wall temperature [12]. The radiation and conduction heat losses to the engine chamber walls, blow-by and crevices are not considered.

The LES is a one-dimensional fluid-dynamic engine simulation code capable of predicting the complete performance of an engine system [11]. The program can be used to calculate:

(a) The full and part load performance of the engine under steady state and transient operations,

(b) the in-cylinder heat transfer data,

(c) the instantaneous gas property variations within the engine manifolds,

(d) turbocharger and supercharger matching conditions.

In the LES code, the flow in the pipes is solved using a one-dimensional model of pipe gas dynamics. The conditions within the pipe elements are calculated at each time step by solving a set of conservation equations for mass, momentum and energy. The equations assume that the gas flow uniformly fills the entire pipe. A shockcapturing finite volume scheme is used to solve the governing equations of gas flow in pipes.

The numerical method used is based on the two-step Lax-Wendroff scheme, used in conjunction with a symmetric non-linear flux limiter, giving second-order spatial and temporal accuracy. This scheme is a member of the class of shock-capturing finite difference schemes that are capable of handling the shock waves and supersonic flows occurring in the manifolds of high-performance engines. The flux limiter, which is based on the total variation diminishing criterion, helps to prevent the occurrence of spurious oscillations in the solution when shock waves and contact discontinuities are encountered [11]. 
The LES program allows the user to build a model of the entire engine by selecting engine components from a toolbox and connecting them by pipe elements.

The simulation is started with the Aurora code which calculates the compression (from IC), autoignition, combustion and expansion (until EO), with a time step of $1^{\circ} \mathrm{CA}$. The initial values of the charge mixture at the IC point, such as temperature, pressure and composition, are assumed. At the end of the expansion stroke, the calculated data of the cylinder pressure, temperature and exhaust gas composition are transferred to the LES code, which uses them as an input. The LES code performs the calculation of the exhaust and intake strokes (from EO to the IC point - the gas exchange process), with the same time step as the Aurora code. The data for the charge mixture temperature, pressure and composition obtained at the end of intake strokes (IC point) are transferred back to the Aurora code and used as an input for the new calculation cycle. The calculation continues until differences between runs reach the convergence criteria.

Aurora is chosen owing to its ability to predict accurately the autoignition of CAI combustion [13-15], while the LES code is employed owing to its ability to model the instantaneous charge mixture properties in the engine manifolds.

\section{MODEL VALIDATION}

The results obtained by using the simulation model are validated against the experimental results. It was found that at least 30 cycles have to be calculated to reach a satisfactory degree of convergence with the experimental results. The engine specification and conditions used in the simulation were the same as those used in the experiment and summarized in Table 1 ( $\varepsilon$ 10.5, engine speed $2000 \mathrm{r} / \mathrm{min}$, bore $\times$ stroke $80.5 \times 88.2 \mathrm{~mm}, 50$ per cent IEGR, gasoline fuel 95RON and stoichiometric equivalence air-fuel ratio). The charge mixture pressure, temperature and composition at the IC point were assumed or estimated. The charge pressure was assumed to be 1 bar (naturally aspirated engine). The charge temperature and composition were estimated from the amount of trapped exhaust gases obtained from the test and by assuming the mixing of ideal gases. The detailed procedure has been reported in references [9], [16] and [17]. The estimated charge temperature was $430 \mathrm{~K}$ and the estimated composition was 50 per cent IEGR and 50 per cent air/fuel charge. It is very important to be able to estimate correctly the charge properties at IC, since it is crucial for the accurate modelling of CAI process ignition. The charge values at IC are instantaneous ones and therefore difficult to measure accurately. These values greatly depend on the fluid-dynamic and gas exchange processes that take place from EO to IC.
For simulation of gasoline fuel 95RON, a mixture of isooctane and $n$-heptane fuels ( $95 \mathrm{vol} \%$ isooctane and $5 \mathrm{vol} \% n$-heptane) is used. The detailed chemical kinetics mechanism for a mixture of isooctane and $n$-heptane fuel, which consists of 1087 species and 4392 reactions with complete $\mathrm{NO}_{x}$ chemistry, has been developed in-house and validated successfully against the available test data. The mechanism is able to predict autoignition behaviour for various fuel research octane numbers $(\mathrm{RON})$ at different temperatures and pressures, and it is explained in detail in reference [18]. The cylinder wall, piston and head are all assumed to be at a uniform temperature of $500 \mathrm{~K}$.

The calculated cylinder pressure history is compared with the cylinder pressure history recorded in the test, and results are presented in Fig. 3a. It can be seen that the general shape of the experimental cylinder pressure curve is well reproduced over the complete cycle. The peak cylinder pressure is overpredicted owing to assumptions that the whole cylinder charge burns simultaneously and completely and owing to the deficiency of the single-zone assumption in modelling the temperature gradient within the charge mixture. In a real engine, the charge mixture inside the cylinder is not uniform in temperature and composition and a small portion of fuel captured in crevices will not burn. Therefore, the pressure gradient after ignition will be lower. On the other hand, the start of autoignition is predicted correctly. The pressure pulses (pressure waves generated by the blowdown and displacement processes) predicted by the LES code, at the start of the gas exchange process (the EO point), are also consistent with the measured pulses. The comparison of calculated and experimental values for several global engine parameters is shown in Table 2.

It can be seen that experimental values are generally well matched within a difference of 10 per cent. The values of the engine parameters such as i.m.e.p., b.m.e.p., indicated power, volumetric efficiency, mechanical efficiency and b.s.f.c. are overpredicted on account of previously mentioned assumptions that the whole charge burns simultaneously and completely. The temperature in the exhaust manifold is matched within a difference of 1.1 per cent, while the difference for the quantity of trapped IEGR is within 4 per cent. It is worth emphasizing that the quantity of trapped IEGR in the experiment was estimated since it could not be measured. The range of differences for the calculated engine parameters seems acceptable considering that the accuracy of the experimental data is not exactly known. Usually with a pressure transducer suited for a thermodynamic evaluation, i.m.e.p. can be determined with less than 3 per cent difference, but sometimes this can be up to 10 per cent [9].

It is worth noting that, with the use of LES code for modelling the exhaust and induction process, the charge properties at IC can be automatically calculated and used as an input to the Aurora code. This is very useful 


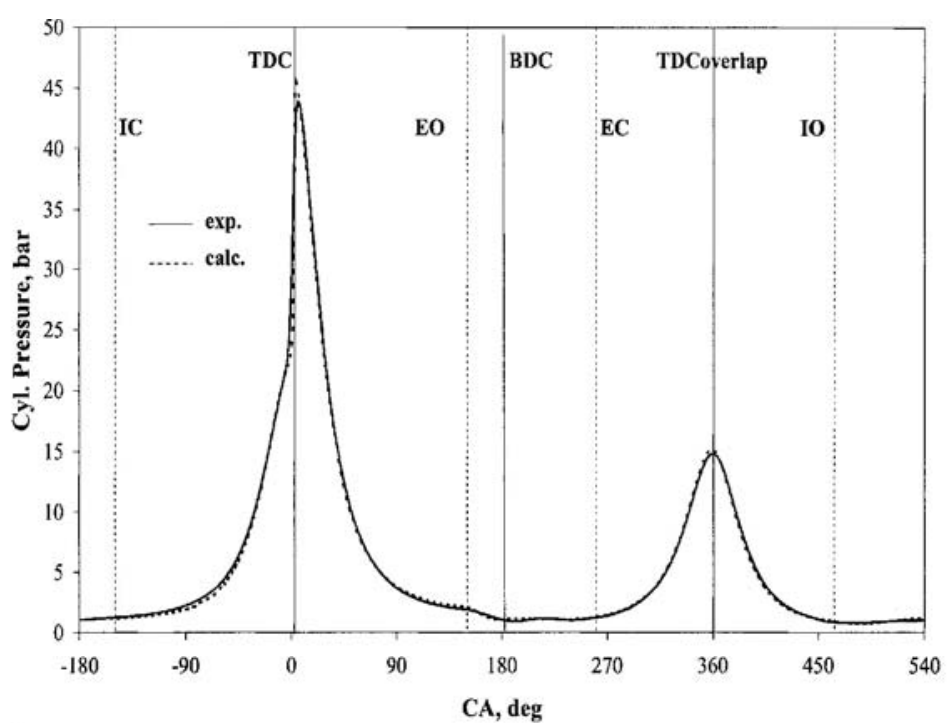

(a)
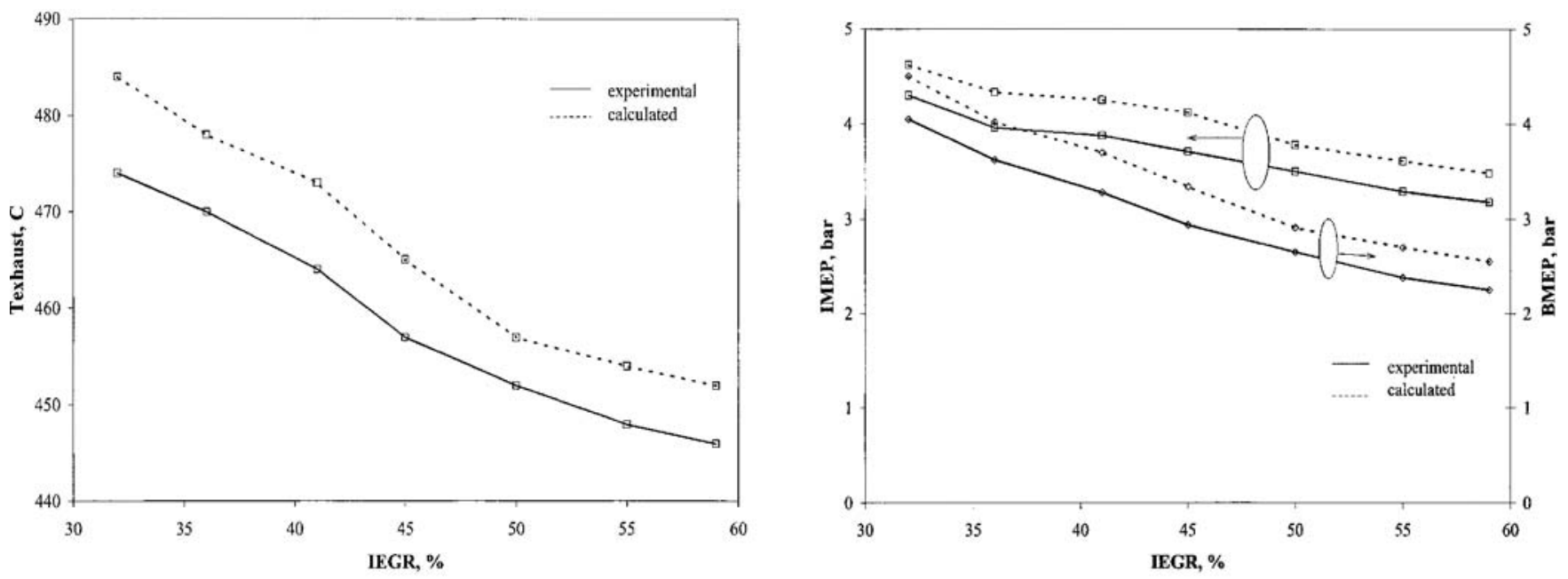

(b)

(c)
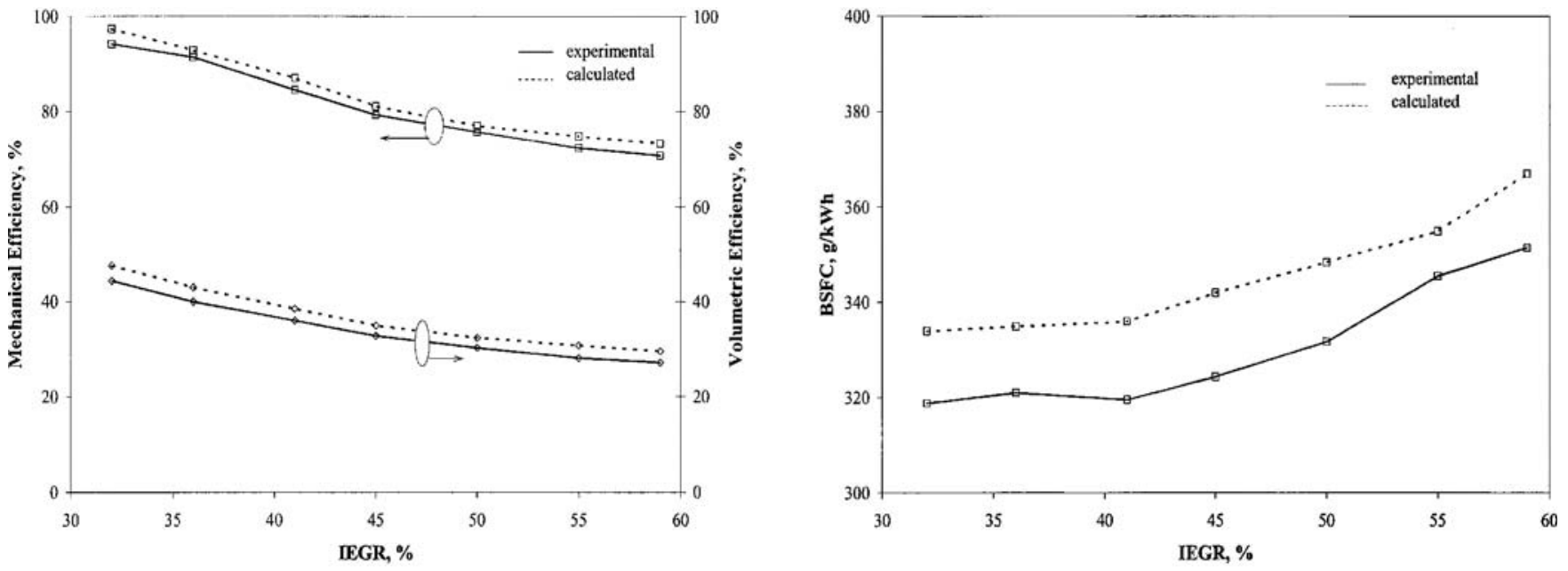

(e)

Fig. 3 Comparison of calculated and experimental values: (a) cylinder pressure histories; (b) exhaust gas temperature; (c) i.m.e.p. and b.m.e.p.; (d) volumetric and mechanical efficiencies; (e) b.s.f.c. 
Table 2 Comparison of calculated and experimental values for several engine parameters

\begin{tabular}{lccc}
\hline Engine parameter & Calculated & Experimental & Difference (\%) \\
\hline i.m.e.p. (bar) & 3.78 & 3.50 & +7.9 \\
b.m.e.p. (bar) & 2.91 & 2.65 & +9.8 \\
Indicated power $(\mathrm{kW})$ & 2.73 & 2.63 & +3.8 \\
Volumetric efficiency (\%) & 32.4 & 30.3 & +6.3 \\
Mechanical efficiency $(\%)$ & 75.2 & 70.4 & +6.8 \\
b.s.f.c. $(\mathrm{g} / \mathrm{kW}$ ) & 348.4 & 331.8 & +5 \\
Temperature in exhaust manifold $\left({ }^{\circ} \mathrm{C}\right)$ & 457 & 452 & +1.1 \\
Temperature at IC point $(\mathrm{K})$ & 419 & & +3.8 \\
IEGR $(\%)$ & 52 & 50 & \\
\hline
\end{tabular}

because the amount of trapped exhaust gas for a camless CAI engine is not exactly known (the amount of trapped exhaust gas is an instantaneous value).

An additional validation of the simulation model is carried out for all other points where the CAI operational mode was achieved. These points are for 32, 36, 41, 45, 55 and 59 per cent IEGR. Comparison of the measured values of the exhaust gas temperature, $T_{\text {exh }}$ (measured in the exhaust manifold), with calculated values is shown in Fig. 3b, comparison of i.m.e.p. and b.m.e.p. measured and calculated values in Fig. 3c, comparison of volumetric and mechanical efficiency values in Fig. 3d and comparison of b.s.f.c. values in Fig. 3e.

It can be seen that the trends of the experimental results are matched with good agreement and that values of $T_{\text {exh }}$, i.m.e.p., b.m.e.p., volumetric efficiency, mechanical efficiency and b.s.f.c. are predicted within a difference of 10 per cent. The differences are consistent with the results obtained for 50 per cent IEGR.

\section{EXPERIMENTAL RESULTS}

Figure 4 shows the measured cylinder pressure histories for different quantities of IEGR obtained by increasing the negative valve overlap. It can be seen that the CAI operation mode is achieved at 32 per cent IEGR and is maintained to 59 per cent IEGR. For values higher than 59 per cent IEGR, the engine is not operated owing to a very low load output, which is inappropriate for the practical application.

For IEGR quantities below 32 per cent, CAI combustion cannot be generated and self-sustained, and it is necessary to use the spark plug. The region below 32 per cent IEGR is not the 'pure' CAI operational mode, but neither is it the 'pure' SI mode, since the spark is only used to ignite the charge mixture, and no turbulent flame propagation is observed in the rest of the unburned mixture. Instead of this, the unburned mixture is autoignited and there is sustained combustion in a uniform

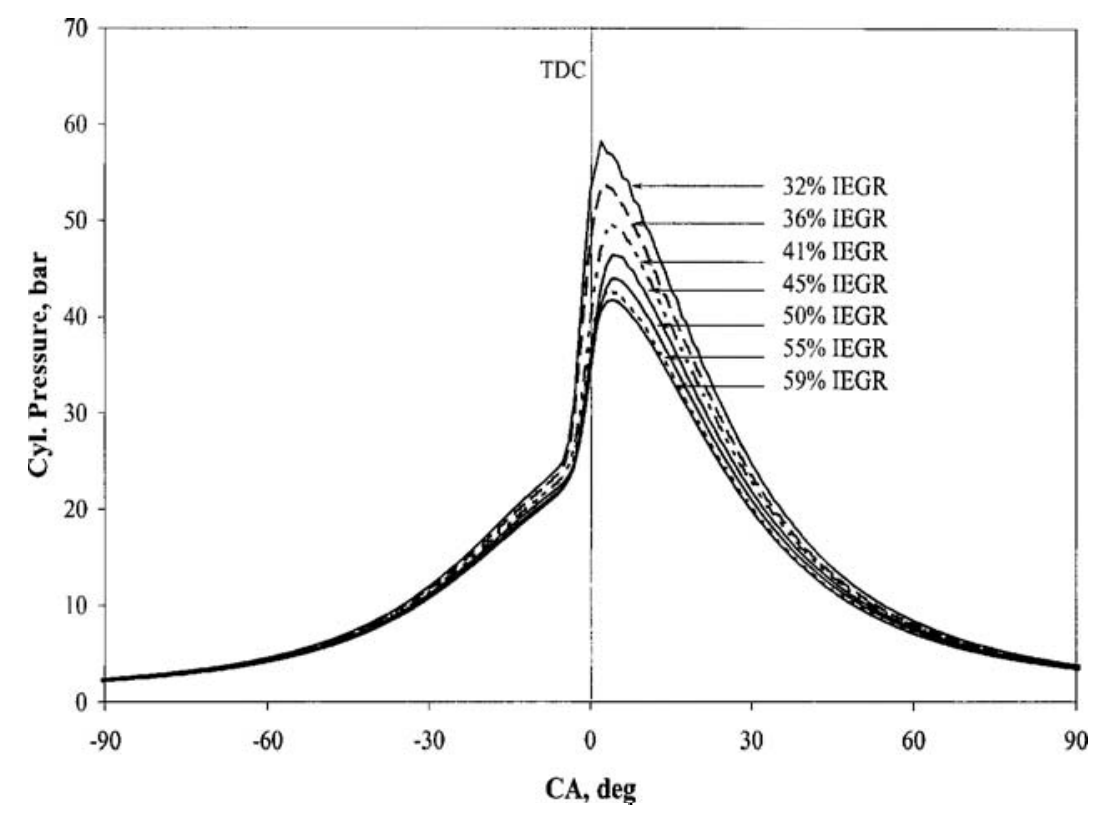

Fig. 4 Experimental cylinder pressure curves for various amounts of IEGR obtained by increasing the negative valve overlap 
and simultaneous autoignition process, as in CAI combustion. This result indicates that activation from the spark plug is not used as an essential combustion source, as in the SI combustion strategy, but only as an assistance to autoignition.

Even though the region below 32 per cent IEGR is not a 'pure' CAI operational mode, it is of great interest to investigate this region since it represents the transient mode between the SI and CAI modes. Therefore, it can provide valuable information about the influence of the variable valve timing strategy on the charge properties and hence the potential to obtain control for transient operation. The importance of this region has been discussed in references [8], [16], [19] and [20].

It can be seen in Fig. 4 that, with a higher amount of IEGR, the peak cylinder pressure is reduced, which is due to the influence of the IEGR chemical effects, as discussed in reference [17]. Ignition timing is not significantly affected by increase in the amount of IEGR, as can be seen in Fig. 5. With the highest amount of IEGR ( 59 per cent IEGR) the ignition timing is advanced only by $2^{\circ} \mathrm{CA}$ compared with 32 per cent IEGR. The data for the ignition timing are obtained using the ACAP data acquisition system from DSP Technologies. The start of ignition is assumed at the point where the cylinder pressure rise deviates from an isentropic or motored cylinder pressure trace. For each point where the CAI operational mode is achieved $(32,36,41,45,55$ and 59 per cent IEGR), an isentropic pressure trace is produced from the 'DSP datasum report'. Then, a fit curve that matches the compression slope and the pumping loop is produced. The point of the cylinder volume where the isentropic curve deviates from the pumping loop (converted to a CA) is used as the start of ignition.

On the other hand, $T_{\text {exh }}$, i.m.e.p., b.m.e.p., volumetric efficiency, mechanical efficiency and b.s.f.c. are appreciably affected by increase in the amount of trapped IEGR, as can be seen in Fig. 3. With increase in the amount of

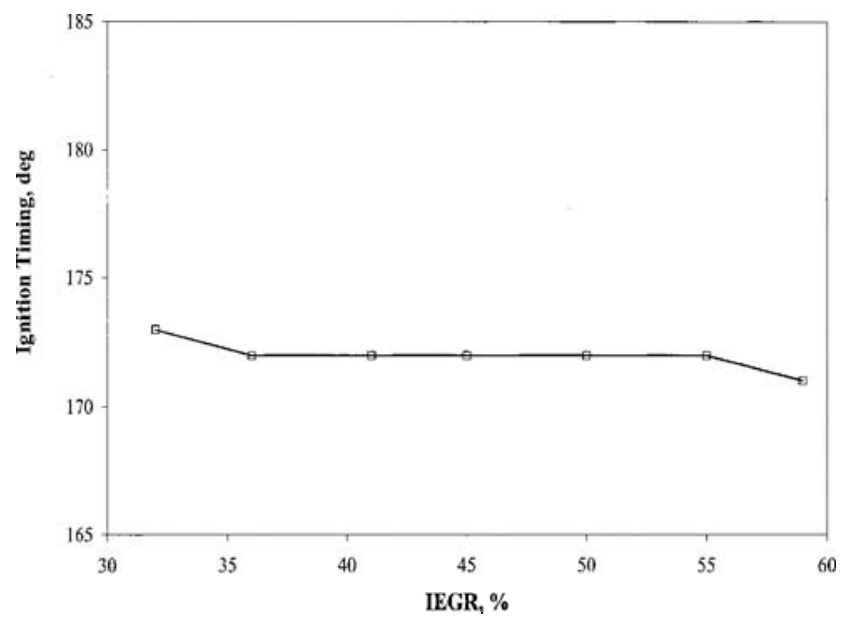

Fig. 5 Ignition timing as a function of different amounts of IEGR trapped IEGR, the i.m.e.p., b.m.e.p., $T_{\text {exh }}$, volumetric efficiency and mechanical efficiency decrease while b.s.f.c. increases. When a greater amount of IEGR is trapped, the amount of fresh air-fuel charge is reduced which results in a lower load output (lower i.m.e.p.) and also in a lower generated torque (lower b.m.e.p.). Consequently, the engine at lower power gives reduced $T_{\text {exh }}$. It can be seen that the b.m.e.p. is affected more by increase in IEGR than is the i.m.e.p. (the b.m.e.p. decreases more steeply than the i.m.e.p.), which in turn influences the mechanical efficiency. The fuel consumption increases with increasing IEGR (with decrease in the load), mainly owing to lower thermal efficiency and high compression of the trapped IEGR which leads to high heat losses.

\section{SIMULATION RESULTS}

\subsection{Analysed valve timing range}

The analysis of the influence of the variable valve timing strategy on the gas exchange process and consequently on the engine parameters (such as trapped gas temperature, IEGR amount, load, pumping losses and volumetric efficiency) and charge mixture properties (composition, temperature and pressure) is carried out by the LES code. The $\varphi_{\mathrm{EC}}$ from 235 to $375^{\circ} \mathrm{CA}$ is investigated (see Fig. 6). The $\varphi_{\mathrm{IO}}$ is varied symmetrically relative to $\mathrm{TDC}_{\text {overlap }}$.

The $\varphi_{\mathrm{EO}}$ and $\varphi_{\mathrm{IC}}$ are kept constant at 145 and $575^{\circ} \mathrm{CA}$ respectively. The other engine parameters, such as the compression ratio, engine speed, intake temperature and equivalence fuel-air ratio are kept constant at the values specified in Table 1.

\subsection{Influence of EC and IO valve timings on engine parameters}

The gas exchange process determines the quantity of IEGR which in turn affects the combustion process and engine performance. The quantity of IEGR influences the charge mixture temperature at the end of the intake
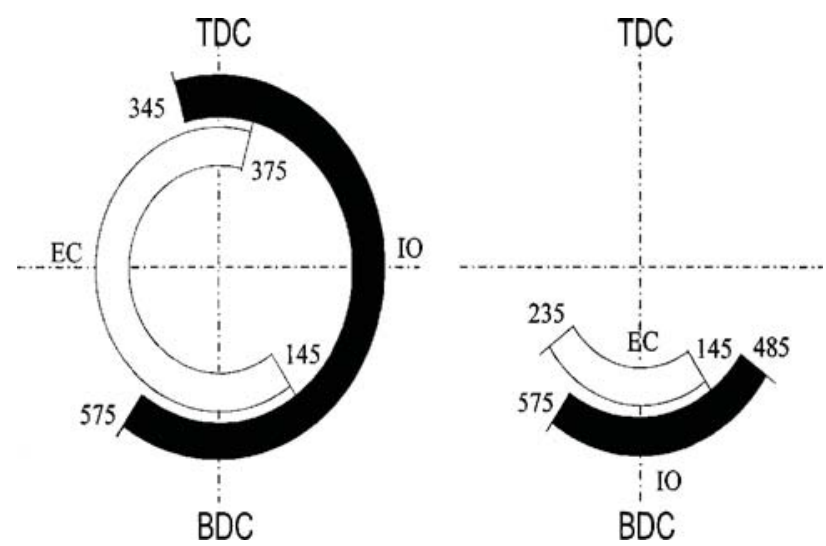

Fig. 6 Analysed valve timings range from the positive to the negative valve overlap (in ${ }^{\circ} \mathrm{CA}$ ) 
stroke (IC point) and therefore the ignition timing and heat release rate. Also, the quantity of IEGR determines the amount of fresh charge and therefore affects the volumetric efficiency and load of the engine.

The changes in IEGR quantity with variations in $\varphi_{\mathrm{EC}}$ and $\varphi_{\mathrm{IO}}$ are shown in Fig. 7a, the changes in i.m.e.p. in Fig. $7 \mathrm{~b}$ and the changes in volumetric efficiency in Fig. $7 \mathrm{c}$.

It can be seen that the IEGR quantity, i.m.e.p. and volumetric efficiency are mainly influenced by the $\varphi_{\mathrm{EC}}$. The IEGR decreases with later EVC, because less exhaust gas is trapped. Therefore, more fresh charge is introduced, resulting in an increase in volumetric efficiency and i.m.e.p.

Overall, the $\varphi_{\text {IO }}$ has considerably less influence on the IEGR quantity, volumetric efficiency and i.m.e.p., except in the two isolated regions ('islands'). These two 'islands' are for a very late $\varphi_{\mathrm{IO}}$ (from 445 to $485^{\circ} \mathrm{CA}$ ) and for a relatively early $\varphi_{\mathrm{IO}}$ (from 355 to $380^{\circ} \mathrm{CA}$ ), while the $\varphi_{\mathrm{EC}}$ range is from 250 to $275^{\circ} \mathrm{CA}$. A very late $\varphi_{\mathrm{IO}}$ causes the trapped exhaust gas to expand to a pressure below the inlet manifold pressure which affects the IEGR quantity and i.m.e.p. With a relatively early $\varphi_{\mathrm{IO}}$, the cylinder pressure is above the intake manifold pressure which causes a reverse flow (at the intake valve) and therefore influences the IEGR quantity and i.m.e.p.

For understanding the physics of the gas exchange process, additional diagrams of the cylinder pressure, temperature and mass flowrate over the exhaust and inlet valves are presented in Fig. 8. Four valve events are analysed (see Table 3): the 'normal' valve event with positive valve overlap (event 1), the event with the biggest negative valve overlap - the earliest $\varphi_{\mathrm{EC}}$ coupled with the latest $\varphi_{\mathrm{IO}}$ (event 4) and two events in-between (events 2 and 3 ). The $\varphi_{\mathrm{IO}}$ is opened symmetrically.

It can be seen that the cylinder pressure, temperature and mass flowrate over the exhaust and inlet valves are closely related to the $\varphi_{\mathrm{EC}}$ and the $\varphi_{\mathrm{IO}}$. For event 1 the cylinder pressure at the EO point has the highest value among the analysed events (see Fig. 8a), since the charge mixture has the highest amount of fuel (the lowest IEGR amount) which in turn produces the highest power output (see Fig. 7a) and therefore the highest cylinder pressure. With increase in the negative valve overlap, the fuel amount in the charge decreases (the strength of the charge mixture decreases), reducing the cylinder pressure.

Table 3 Sequence of four different valve events

\begin{tabular}{lllll}
\hline $\begin{array}{l}\text { Sequence } \\
\text { number }\end{array}$ & $\begin{array}{l}\varphi_{\mathrm{EO}} \\
\left({ }^{\circ} \mathrm{CA}\right)\end{array}$ & $\begin{array}{l}\varphi_{\mathrm{EC}} \\
\left({ }^{\circ} \mathrm{CA}\right)\end{array}$ & $\begin{array}{l}\varphi_{\mathrm{IO}} \\
\left({ }^{\circ} \mathrm{CA}\right)\end{array}$ & $\begin{array}{l}\varphi_{\mathrm{IC}} \\
\left({ }^{\circ} \mathrm{CA}\right)\end{array}$ \\
\hline 1 & 145 & 375 & 345 & 575 \\
2 & 145 & 315 & 405 & 575 \\
3 & 145 & 275 & 445 & 575 \\
4 & 145 & 235 & 485 & 575 \\
\hline
\end{tabular}

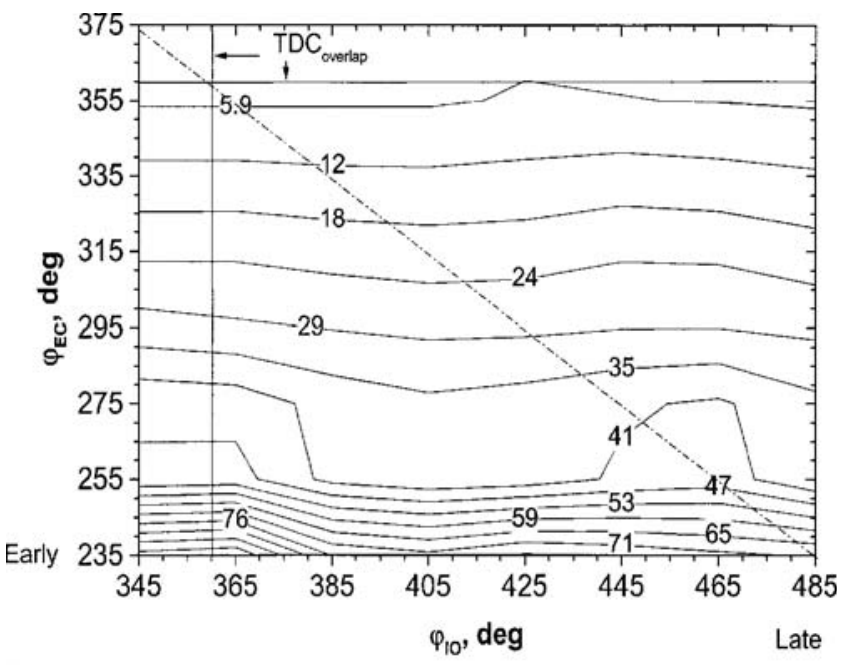

(a)

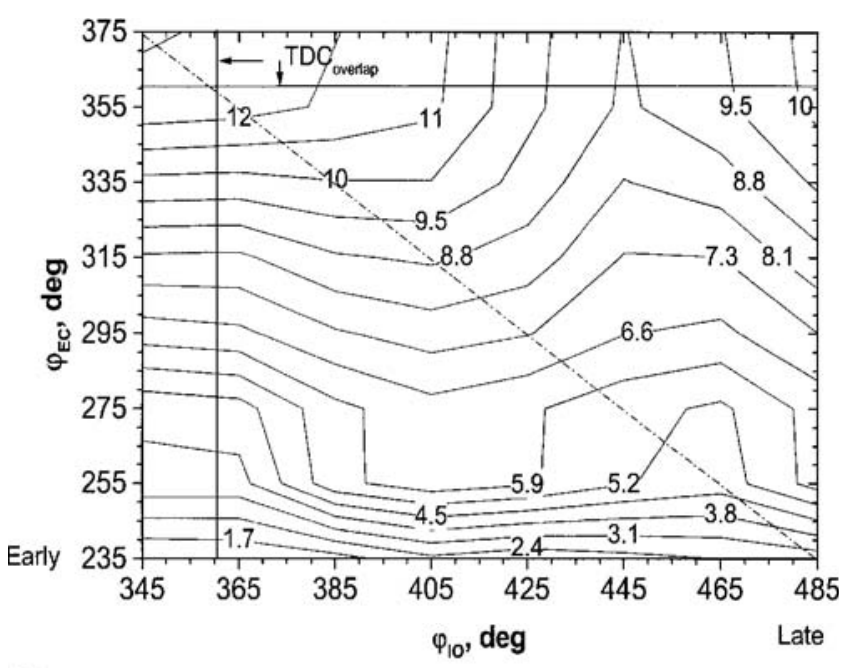

(b)

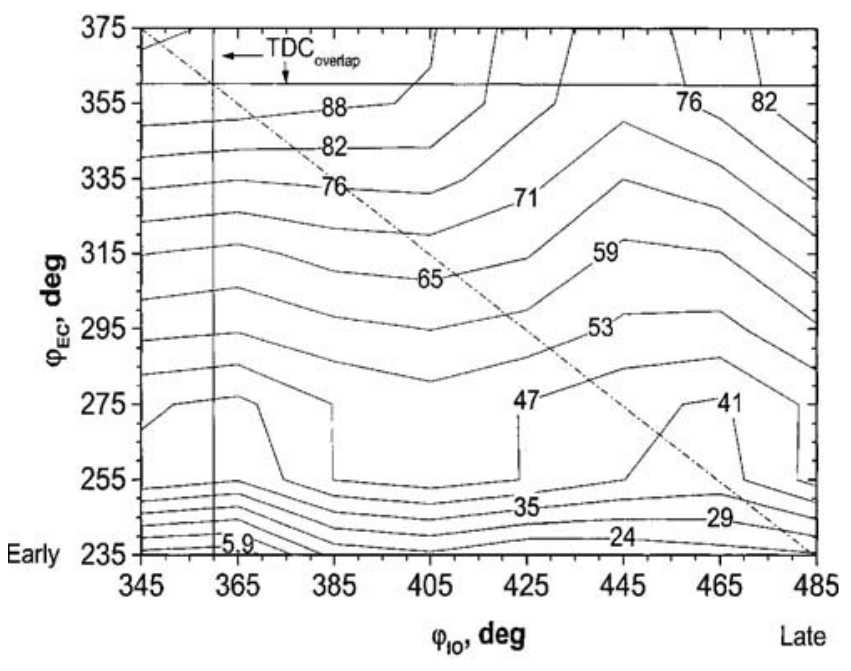

(c)

Fig. 7 (a) IEGR quantity, (b) i.m.e.p. and (c) volumetric efficiency as a function of $\varphi_{\mathrm{EC}}$ and $\varphi_{\mathrm{IO}}$ 


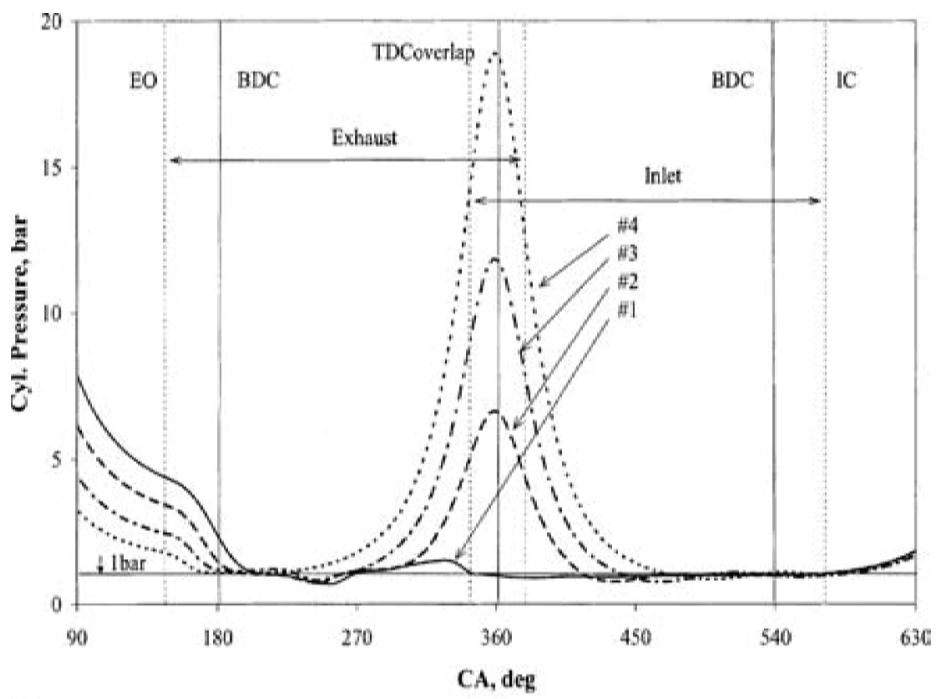

(a)

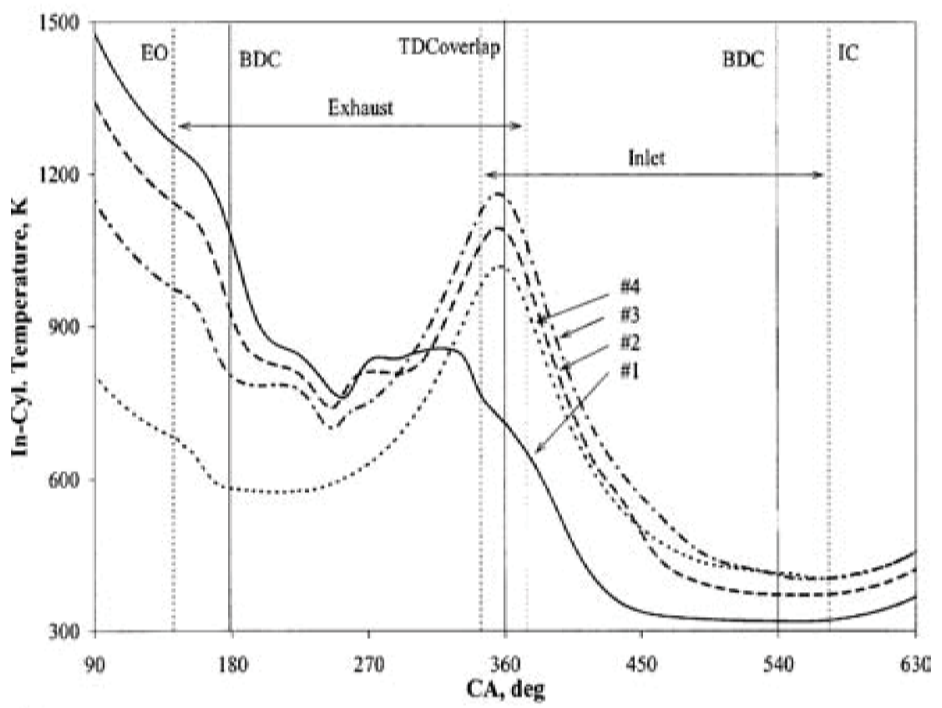

(b)

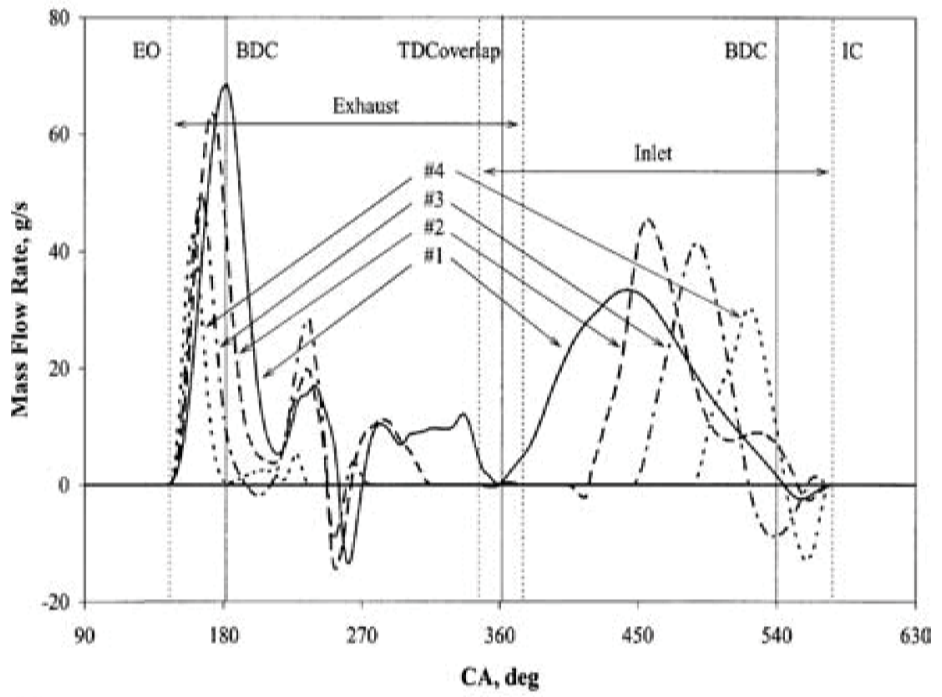

(c)

Fig. 8 (a) Cylinder pressure, (b) in-cylinder temperature and (c) mass flowrate over the exhaust and intake valves as a function of $\varphi_{\mathrm{EC}}$ and $\varphi_{\mathrm{IO}}$ 
However, the situation changes in the exhaust stroke (when the transition from blowdown to displacement occurs), and the cylinder pressure reaches its highest value for event 4 (the weakest mixture) and its lowest value for event 1 (the strongest mixture). This is mainly influenced by the $\varphi_{\mathrm{EC}}$, as it occurs increasingly early with increasing amount of compression. At the end of the intake stroke the cylinder pressure has approximately the same value for all events (with negligible differences).

The in-cylinder temperature (see Fig. 8b) has a similar behaviour at the EO point to the cylinder pressure: it decreases with increase in the negative valve overlap (with decrease in the amount of fuel in the charge mixture), and therefore the highest value is reached for event 1 and the lowest value for event 4 . On the other hand, the in-cylinder temperature (the charge temperature) exhibits different behaviour in the exhaust stroke. At $\mathrm{TDC}_{\text {overlap }}$ it reaches its minimum value for event 1 and its maximum value for event 3 (in the order $3>2>4>1$ from the highest to the lowest value), while at the IC point the order is changed to $4>3>2>1$. This complex behaviour is most probably influenced by many factors such as the boundary conditions (the state at EO), the pressure changes caused by the piston movement and indirectly by the valve movement, the amount of compression heating and the IEGR quantity. Detailed analysis of the cylinder temperature at characteristic points will be presented in section 7.4

It can be seen that the mass flowrates over the exhaust and inlet valves, presented in Fig. 8c, are influenced by the $\varphi_{\mathrm{EC}}$ and the $\varphi_{\mathrm{IO}}$. As the $\varphi_{\mathrm{EC}}$ occurs early (and the $\varphi_{\mathrm{IO}}$ symmetrically late), the exhaust and the intake flows decrease. Decrease in the mass flowrate over the exhaust and intake valves, together with a shorter duration of the exhaust event (the period between EO and the EC) and the intake event (the period between IO and IC), reduces the mass of exhaust gases exhaled and the mass of fresh fuel-air charge inhaled. As a result, the engine parameters are affected (see Fig. 7).

It can be noted that the exhaust flow reaches its first maximum at the valve maximum open point (MOP). The second maximum occurs later and is a consequence of the waves generated by the piston and the valve opposite movements. The exhaust process begins with $\mathrm{EO}$, and, until about $\mathrm{BDC}$, the exhaust gases are discharged owing to the pressure difference between the cylinder and the exhaust system. After BDC, the cylinder is cleaned by the piston as it moves towards TDC. The reverse flow at the exhaust valve (events 1, 2 and 3 ) occurs because the cylinder pressure is lower than the pressure in the exhaust manifold.

It can be noted that the intake flow, for all events, experiences a reverse flow near the end of the intake period, since the inlet valve is closed after the start of the compression stroke ( $\mathrm{IC}$ at $575^{\circ} \mathrm{CA}$ ) and therefore the cylinder pressure rises above the intake manifold pressure (see Fig. 8a). This is an inevitable consequence of the $\varphi_{\text {IC }}$ chosen to take advantage of the ram effect at high speeds [even though the experiment and simulation were performed for a speed of $2000 \mathrm{r} / \mathrm{min}$, in ongoing (and future) investigations it is planned to cover a speed range up to $7000 \mathrm{r} / \mathrm{min}]$.

The velocity obtained at the exhaust valve (during the exhaust process) varies from $\approx 150 \mathrm{~m} / \mathrm{s}$ (event 1 ) to $\approx 70 \mathrm{~m} / \mathrm{s}$ (event 4 ). The velocity at the intake valve (during the intake process) is in the range from $\approx 45 \mathrm{~m} / \mathrm{s}$ (event 1 ) to $\approx 65 \mathrm{~m} / \mathrm{s}$ (event 4 ).

The influence of the $\varphi_{\mathrm{EC}}$ and $\varphi_{\mathrm{IO}}$ timing on the engine pumping losses is shown in Fig. 9a. The pumping losses are evaluated from the i.m.e.p. for the exhaust and intake strokes.

It can be seen that the minimum pumping losses take place for the symmetrical $\varphi_{\mathrm{EC}}$ and $\varphi_{\mathrm{IO}}$. When the $\varphi_{\mathrm{IO}}$ is opened symmetrically, the in-cylinder pressure is near or equal to the intake manifold pressure and the minimum

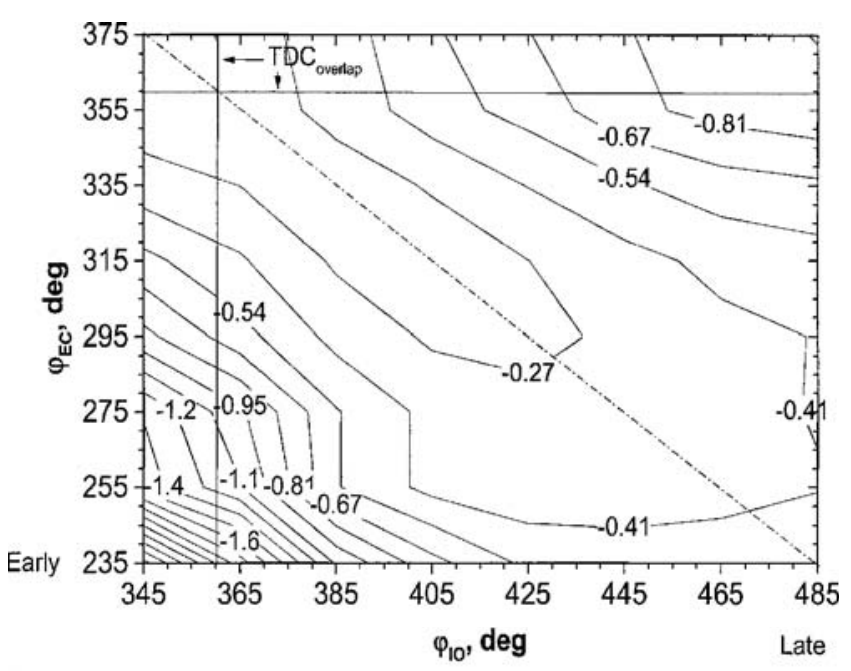

(a)

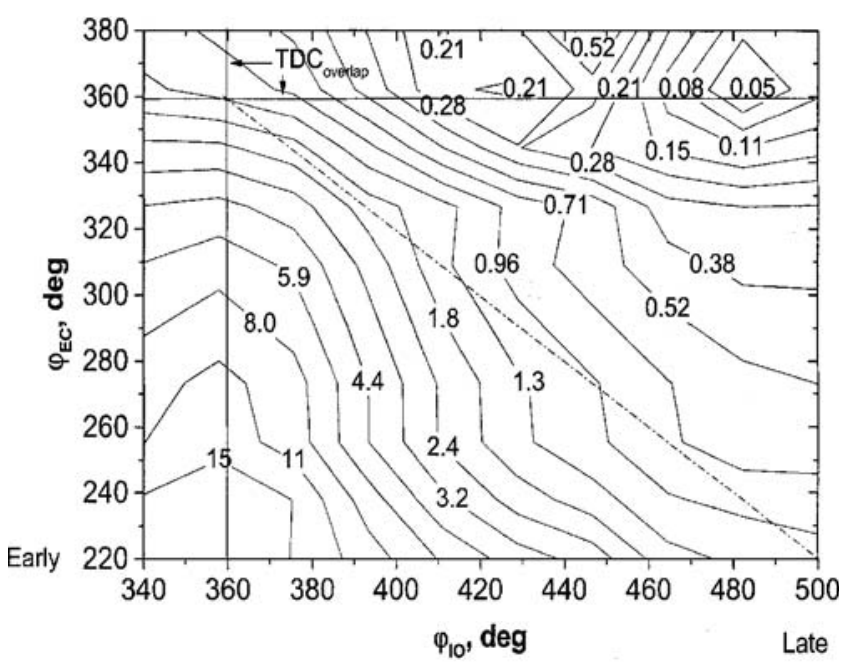

(b)

Fig. 9 (a) Pumping losses and (b) cylinder pressure values at the IO point as a function of $\varphi_{\mathrm{EC}}$ and $\varphi_{\mathrm{IO}}$

Proc. Instn Mech. Engrs Vol. 218 Part D: J. Automobile Engineering 
pumping losses occur. For a given $\varphi_{\mathrm{IO}}$, the $\varphi_{\mathrm{IO}}$ required for minimum pumping loss can be found from the dashed line in Fig. 9a.

A late $\varphi_{\mathrm{IO}}$ causes the trapped exhaust gas to expand to a pressure below the intake manifold pressure, as can be seen in Fig. 9b, which increases the pumping losses. On the other hand, with an early $\varphi_{\mathrm{IO}}$, the cylinder pressure is above the intake manifold pressure, which causes reverse flow at the intake valve and thus an increase in the pumping losses.

From the experiments performed on the singlecylinder engine and the conditions specified in Table 1 it is found that CAI combustion can be generated and selfsustained only for quantities of IEGR above 32 per cent. For an IEGR quantity below this value, CAI combustion cannot be generated and self-sustained without the use of a spark plug (transient mode). The maximum quantity of IEGR is constrained by the engine design to 80 per cent IEGR.

Taking into account the importance of the transient mode and limitations of the engine design, the region from 23 per cent IEGR (transient mode) to 80 per cent IEGR is chosen for the investigation of the influence of $\varphi_{\mathrm{EC}}$ and $\varphi_{\mathrm{IO}}$ on the charge properties in engine manifolds. It can be seen in Fig. 7a that this range of IEGR is obtained for the $\varphi_{\mathrm{EC}}$ from 235 to $315^{\circ} \mathrm{CA}$ and the symmetrical $\varphi_{\mathrm{IO}}$ from 405 to $485^{\circ} \mathrm{CA}$ (with a step of $5^{\circ} \mathrm{CA}$ ).

\subsection{Influence of the $\mathrm{EC}$ and IO valve timings on charge mixture properties}

To explain the effects of the $\varphi_{\mathrm{EC}}$ and the $\varphi_{\mathrm{IO}}$ on the charge mixture properties, two additional sets of diagrams for the cylinder pressure, temperature and mass flowrate over the exhaust and inlet valves are analysed. The first set of diagrams (presented in Fig. 10) analyses the influence of the $\varphi_{\mathrm{IO}}$ only and is obtained for a fixed $\varphi_{\mathrm{EC}}$ while varying the $\varphi_{\mathrm{IO}}$. Five events are analysed (see Table 4 ): early $\varphi_{\mathrm{IO}}$ (events 1 and 2 ), symmetrical $\varphi_{\mathrm{IO}}$ (event 3 ) and late $\varphi_{\mathrm{IO}}$ (events 4 and 5 ). An early $\varphi_{\mathrm{IO}}$ event (events 1 and 2) or a late $\varphi_{\mathrm{IO}}$ event (events 4 and 5) is related to the symmetrical $\varphi_{\mathrm{IO}}$ event (event 3 ).

The second set of diagrams (presented in Fig. 11) analyses the influence of the $\varphi_{\mathrm{EC}}$ only and is obtained for a fixed $\varphi_{\mathrm{IO}}$ while varying the $\varphi_{\mathrm{EC}}$. Five events, as in the analysis of the $\varphi_{\mathrm{IO}}$ influence, are investigated (see Table 5). Events 1 and 2 represent an early $\varphi_{\mathrm{EC}}$,

Table 4 Sequence of valve events for a fixed $\varphi_{\mathrm{EC}}$

\begin{tabular}{lllll}
\hline $\begin{array}{l}\text { Sequence } \\
\text { number }\end{array}$ & $\begin{array}{l}\varphi_{\mathrm{EO}} \\
\left({ }^{\circ} \mathrm{CA}\right)\end{array}$ & $\begin{array}{l}\varphi_{\mathrm{EC}} \\
\left({ }^{\circ} \mathrm{CA}\right)\end{array}$ & $\begin{array}{l}\varphi_{\mathrm{IO}} \\
\left({ }^{\circ} \mathrm{CA}\right)\end{array}$ & $\begin{array}{l}\varphi_{\mathrm{IC}} \\
\left({ }^{\circ} \mathrm{CA}\right)\end{array}$ \\
\hline 1 & 145 & 285 & 405 & 575 \\
2 & 145 & 285 & 415 & 575 \\
3 & 145 & 285 & 435 & 575 \\
4 & 145 & 285 & 455 & 575 \\
5 & 145 & 285 & 465 & 575 \\
\hline
\end{tabular}

Proc. Instn Mech. Engrs Vol. 218 Part D: J. Automobile Engineering
Table 5 Sequence of valve events for a fixed $\varphi_{\text {IO }}$

\begin{tabular}{lllll}
\hline $\begin{array}{l}\text { Sequence } \\
\text { number }\end{array}$ & $\begin{array}{l}\varphi_{\mathrm{EO}} \\
\left({ }^{\circ} \mathrm{CA}\right)\end{array}$ & $\begin{array}{l}\varphi_{\mathrm{EC}} \\
\left({ }^{\circ} \mathrm{CA}\right)\end{array}$ & $\begin{array}{l}\varphi_{\mathrm{IO}} \\
\left({ }^{\circ} \mathrm{CA}\right)\end{array}$ & $\begin{array}{l}\varphi_{\mathrm{IC}} \\
\left({ }^{\circ} \mathrm{CA}\right)\end{array}$ \\
\hline 1 & 145 & 315 & 435 & 575 \\
2 & 145 & 305 & 435 & 575 \\
3 & 145 & 285 & 435 & 575 \\
4 & 145 & 265 & 435 & 575 \\
5 & 145 & 255 & 435 & 575 \\
\hline
\end{tabular}

event 3 represents a symmetrical $\varphi_{\mathrm{EC}}$ and events 4 and 5 represent a late $\varphi_{\mathrm{EC}}$. An early $\varphi_{\mathrm{EC}}$ or a late $\varphi_{\mathrm{EC}}$, as in the case of the $\varphi_{\mathrm{IO}}$, is related to the symmetrical $\varphi_{\mathrm{EC}}$.

It can be seen in Fig. 10a that the cylinder pressure at the EO point decreases with later $\varphi_{\mathrm{IO}}$. In the exhaust and the intake strokes the $\varphi_{\text {IO }}$ has a weak influence on the cylinder pressure, and it remains almost constant (with a small difference at the $\mathrm{TDC}_{\text {overlap }}$ point and in the second part of the intake stroke after the IO point). At the end of the intake stroke (IC point) the cylinder pressure has the same value for all events (with negligible differences).

It can be noted that, with changes in $\varphi_{\text {IO }}$, the in-cylinder temperature (the charge temperature) at the EO point exhibits a similar behaviour to the cylinder pressure: it decreases with later $\varphi_{\mathrm{IO}}$ (see Fig. 10b). In the exhaust stroke the $\varphi_{\text {IO }}$ has a negligible influence on the in-cylinder temperature (like that on the cylinder pressure), and thus it remains constant. However, the differences obtained during the intake stroke and at the IC point are much higher, resulting in an increase in the in-cylinder temperature with a late $\varphi_{\mathrm{IO}}$ (the highest temperature is obtained for event 5 and the lowest for event 1$)$. This is a consequence of the reverse flow at the IO that exists in early $\varphi_{\mathrm{IO}}$ - events 1 and 2 (see Fig. 10c). As the piston moves downwards, the reverse-flow gases and the fresh air-fuel charge are sucked back into the cylinder in the same cycle. Therefore, there are some heat losses from the reverse gas flow to the cold intake manifold walls and the reverse-flow gas is cooled down, thus lowering the in-cylinder temperature.

It can be seen in Fig. 10c that, with changes in the $\varphi_{\mathrm{IO}}$, the exhaust flow is little affected: it increases with an early $\varphi_{\text {IO }}$ (events 1 and 2 ) and decreases with a late $\varphi_{\text {IO }}$ (events 4 and 5). With an early $\varphi_{\text {IO }}$ the cylinder pressure (during the blowdown process) has a higher value than the pressure in the exhaust manifold (see Fig. 10a), and therefore a higher flowrate occurs.

The intake flow is strongly affected by the $\varphi_{\mathrm{IO}}$ (see Fig. 10c). If the $\varphi_{\mathrm{IO}}$ is early, the cylinder pressure is higher than the intake manifold pressure and there is a reverse flow from the cylinder into the intake manifold. The reverse flow increases with the earlier $\varphi_{\mathrm{IO}}$, since the driving force is the pressure difference between the cylinder and the intake manifold. With the later $\varphi_{\mathrm{IO}}$ there is a reverse flow near the end of the intake period, since the cylinder pressure rises above the intake manifold 


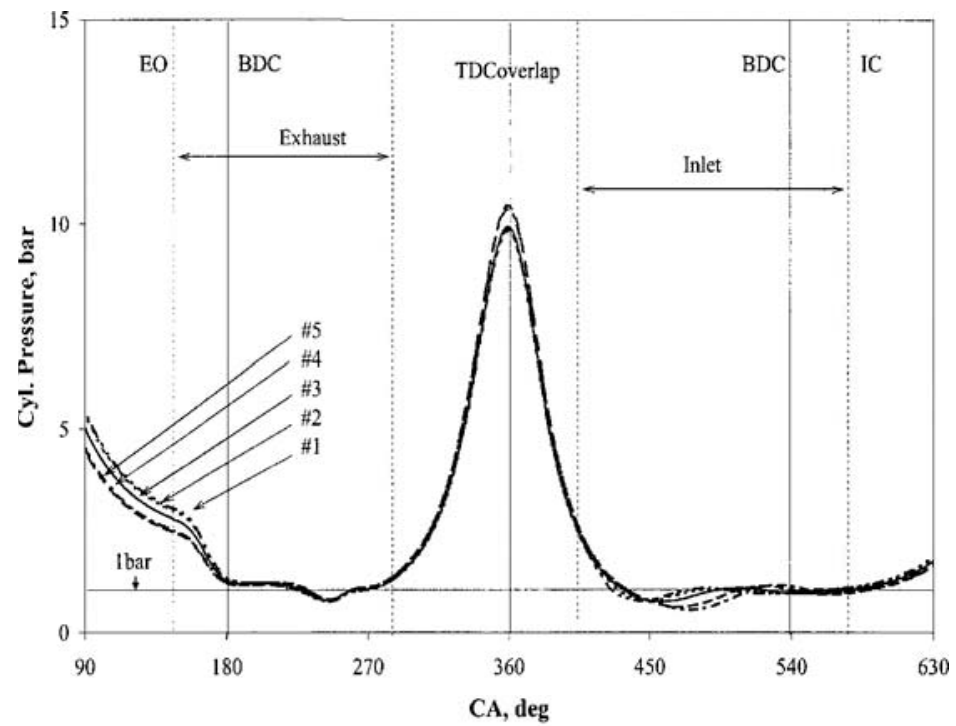

(a)

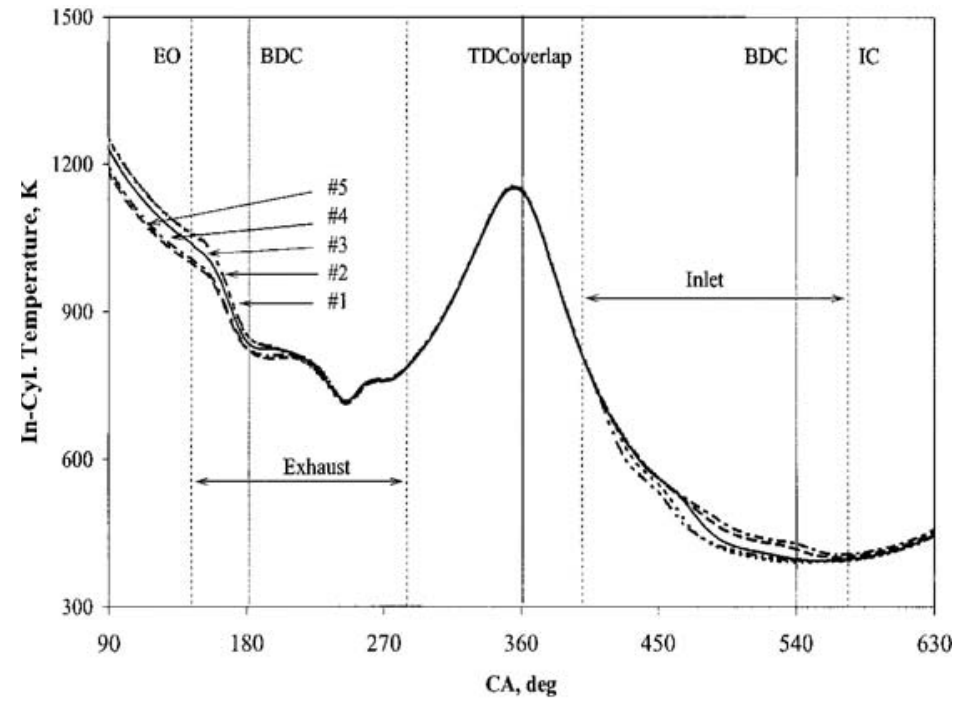

(b)

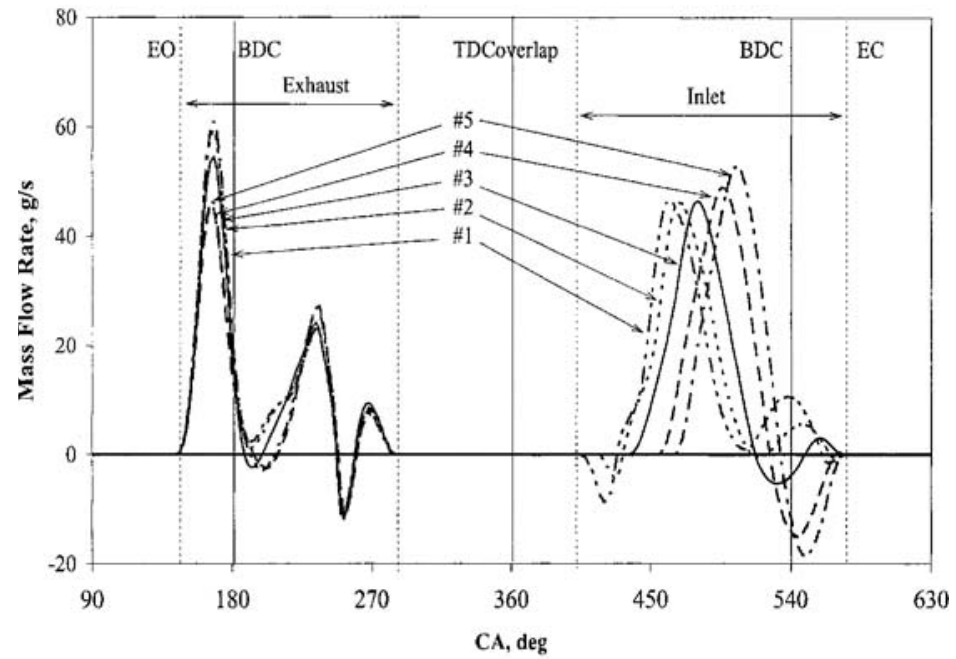

(c)

Fig. 10 (a) Cylinder pressure, (b) in-cylinder temperature and (c) mass flowrate over the exhaust and intake valves as a function of $\varphi_{\mathrm{IO}}\left(\varphi_{\mathrm{EC}}\right.$ fixed at $\left.385^{\circ} \mathrm{CA}\right)$ 


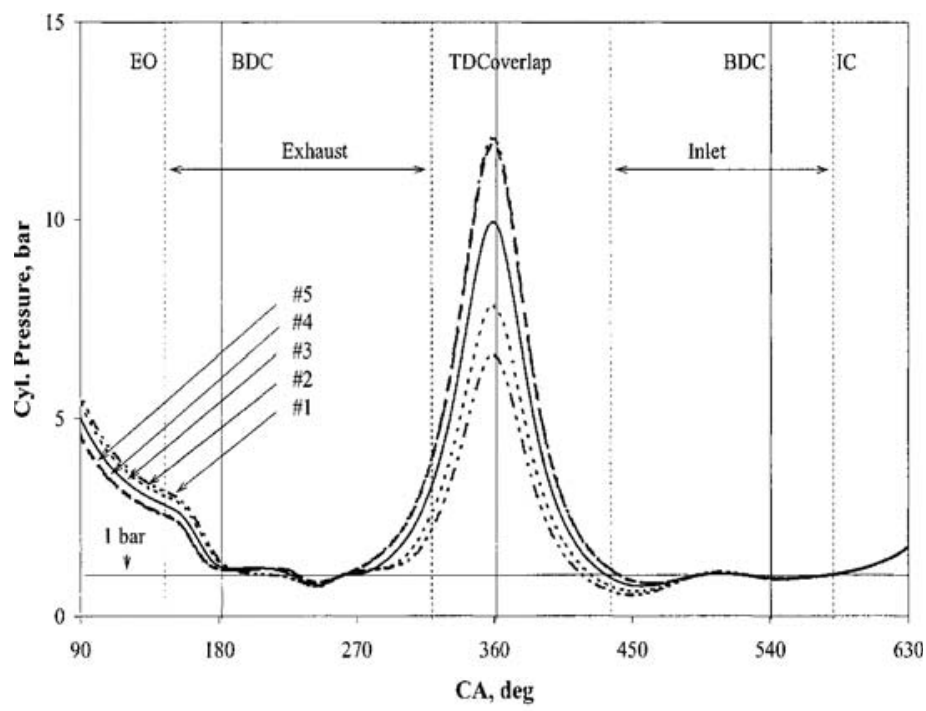

(a)

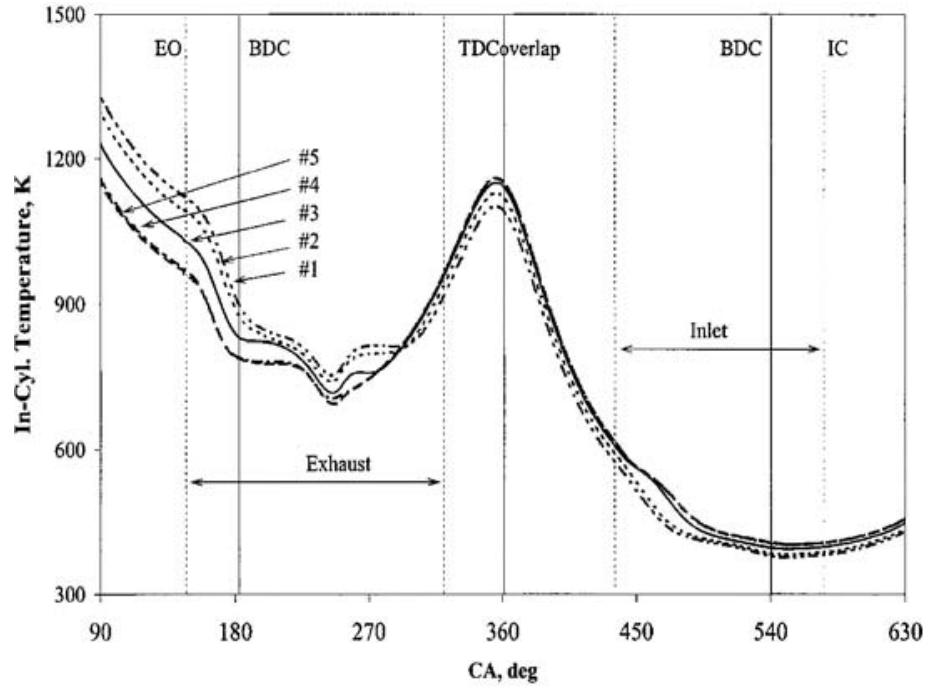

(b)

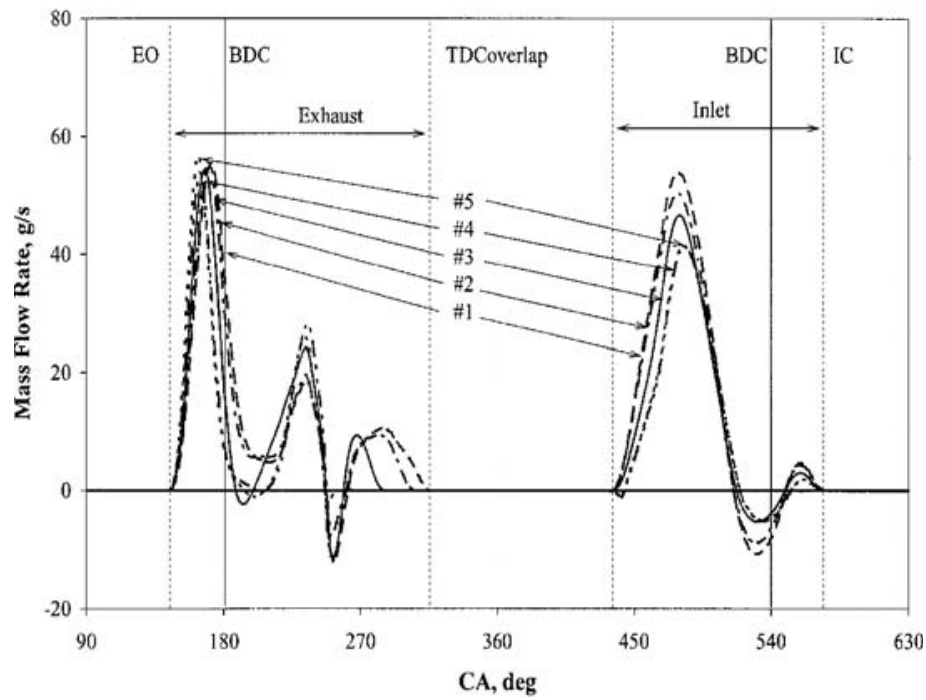

(c)

Fig. 11 (a) Cylinder pressure, (b) in-cylinder temperature and (c) mass flowrate over the exhaust and intake valves as a function of $\varphi_{\mathrm{EC}}\left(\varphi_{\mathrm{IO}}\right.$ fixed at $\left.435^{\circ} \mathrm{CA}\right)$ 
pressure (see Fig. 10a). This is an inevitable consequence of the $\varphi_{\text {IC }}$ chosen (after the start of the compression stroke at $575^{\circ} \mathrm{CA}$ ) to take advantage of the ram effect at high speeds, as discussed in section 7.2. As the results show, the pumping loss is strongly influenced by the reverse flow, i.e. $\varphi_{\text {IO }}$ (see Fig. 9a), while the influence on other engine parameters is less (see Fig. 7)

It can be seen that the changes in the $\varphi_{\mathrm{EC}}$ have a weak effect on the cylinder pressure at the EO point: it decreases with the earlier $\varphi_{\mathrm{EC}}$ (see Fig. 11a). In the exhaust and intake strokes, changes in the $\varphi_{\mathrm{EC}}$ have a pronounced influence on the cylinder pressure. With the earlier $\varphi_{\mathrm{EC}}$ the amount of compression is higher, resulting in an increase in the cylinder pressure (the highest value is obtained for event 5 and the lowest for event 1). At the end of the intake stroke (at the IC point) the cylinder pressure has approximately the same values for all events.

It can be seen that, with changes in $\varphi_{\mathrm{EC}}$, the in-cylinder temperature (the charge temperature) at the EO point exhibits similar behaviour to the cylinder pressure: it decreases with the earlier $\varphi_{\mathrm{EC}}$ (see Fig. 10b). However, the in-cylinder temperature shows different behaviour in the exhaust and intake strokes: it increases with an early $\varphi_{\mathrm{EC}}$ (approximately from the second part of the exhaust stroke), reaching its highest value for event 5 and its lowest value for event 1 . At the end of the intake stroke (at the IC point) the in-cylinder temperature retains the same order. With an early $\varphi_{\mathrm{EC}}$ the in-cylinder temperature increases owing to a longer compression duration.

The effects of the $\varphi_{\mathrm{EC}}$ on the exhaust and intake flows is shown in Fig. 11c. It can be seen that both the exhaust and the intake flowrates are affected by the $\varphi_{\mathrm{EC}}$ and hence the exhaust gases exhaled and the fresh air-fuel charge inhaled. Consequently, the engine parameters are affected with the mass exhaled/inhaled, i.e. $\varphi_{\mathrm{EC}}$ (see Fig. 7).

It can be noted that the exhaust flow increases with a late $\varphi_{\mathrm{EC}}$. A late $\varphi_{\mathrm{EC}}$ in conjunction with a longer duration of the exhaust event increases the mass of exhaust gases exhaled.

The intake flow also increases with a late $\varphi_{\mathrm{EC}}$. With a late $\varphi_{\mathrm{EC}}$ the amount of retained exhaust gases in the cylinder (IEGR) decreases, leading to a higher amount of fresh air-fuel charge inhaled. From the analysis performed it can be concluded that the $\varphi_{\mathrm{EC}}$ has the stronger influence on the charge mixture properties and engine parameters during the GEP in comparison with the influence of the $\varphi_{\mathrm{IO}}$.

Since the charge mixture temperature at the IC point plays an important role in the control of CAI combustion (most likely the most important role), its change with variations in the $\varphi_{\mathrm{EC}}$ and $\varphi_{\mathrm{IO}}$ will be discussed in detail. However, owing to the large number of investigated points for the analysed range of $\varphi_{\mathrm{EC}}$ and $\varphi_{\mathrm{IO}}$ (289 points) (and thus the impossibility of showing, for all of them, diagrams of the pressure, temperature and mass flowrate over the exhaust and intake valves), the changes in the charge mixture temperature at the IC point are presented in the format of a two-dimensional diagram (the $x$ axis relates to $\varphi_{\mathrm{IO}}$ and the $y$ axis to $\varphi_{\mathrm{EC}}$ ). The dashed-dotted line represents the line of symmetry (to the $\mathrm{TDC}_{\text {overlap }}$ ).

\subsubsection{Influence on the charge mixture temperature at the IC point}

The effect of the $\varphi_{\mathrm{EC}}$ and $\varphi_{\mathrm{IO}}$ on the charge mixture temperature at the IC point is shown in Fig. 12. This temperature is closely related to the boundary conditions at EO, the pressure changes caused by the piston movement and indirectly by the valve movement, the IEGR quantity, the amount of compression during the exhaust stroke, the mixing of the IEGR and fresh air-fuel charge (after IO) and the intake air temperature. It can be seen that the temperature of the resulting charge mixture varies considerably (from 379 to $424 \mathrm{~K}$ ) and that three regions exist in which the temperature is determined only by the $\varphi_{\mathrm{EC}}$ or only by the $\varphi_{\mathrm{IO}}$ or by both timings.

In the first region, a very early $\varphi_{\mathrm{EC}}$ (from 235 to $245^{\circ} \mathrm{CA}$ ), the temperature is determined mainly by the $\varphi_{\mathrm{EC}}$. This region is characterized by the highest charge mixture temperature ( $424 \mathrm{~K}$ ) and the highest temperature gradient (from 424 to $382 \mathrm{~K}$ ).

The highest mixture temperature achieved in this region $(424 \mathrm{~K})$ is due to the mixing of a large amount of hot IEGR (about 70 per cent) with a small amount of cold fresh air-fuel charge. The charge mixture in this region has a high temperature combined with a high dilution, which is very favourable for CAI combustion, as discussed in references [15], [19] and [21]. It can be expected that this mixture will autoignite relatively early in the following cycle, producing a less intense heat release rate (longer combustion duration) and low peak cylinder pressure. This behaviour has been reported in references [19] and [21].

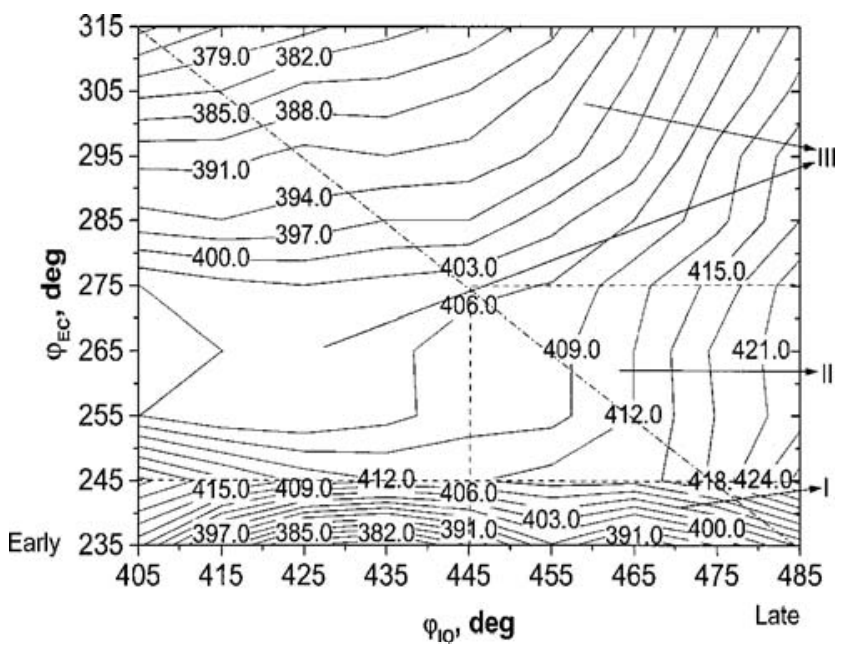

Fig. 12 Charge mixture temperature at the IC point as a function of $\varphi_{\mathrm{EC}}$ and $\varphi_{\mathrm{IO}}$ (in $\mathrm{K}$ )

Proc. Instn Mech. Engrs Vol. 218 Part D: J. Automobile Engineering 
The highest temperature gradient in this region is mainly the consequence of a significant temperature difference obtained during the exhaust stroke (during the compression of the IEGR) and the existence of reverse flow (at the intake valve) at an asymmetrical $\varphi_{\text {IO }}$ (see Figs $10 \mathrm{~b}$ and c respectively).

The temperature in the second region $\left(\varphi_{\mathrm{EC}}\right.$ from 245 to $275^{\circ} \mathrm{CA}$ and $\varphi_{\mathrm{IO}}$ from 445 to $485^{\circ} \mathrm{CA}$ ) is primarily influenced by the $\varphi_{\mathrm{IO}}$. The temperature in this region changes from 421 to $406 \mathrm{~K}$ which is considerably lower in comparison with the change in the first region. Also, it can be noted that the temperature gradient in this region is considerably lower than that in the first region.

In the second region the IEGR quantity is nearly constant ( $\approx 40$ per cent) (see Fig. $7 \mathrm{a}$ ), and therefore the mixing and gas exchange processes are mainly determined by the amount of fresh charge, i.e. by $\varphi_{\mathrm{IO}}$ timing. A low variation in charge mixture temperature is probably influenced by the $\varphi_{\mathrm{IO}}$, i.e. by the non-existence of reverse flow (at the intake valve), at the beginning of the intake process, for a late $\varphi_{\mathrm{IO}}$. The mixture in this region will be expected to autoignite later than the mixture in the first region and to produce a higher heat release rate and peak cylinder pressure. This observation has been reported in references [19] and [21].

The rest of the map is the third region where the temperature is affected by both $\varphi_{\mathrm{EC}}$ and $\varphi_{\mathrm{IO}}$. The temperature of the resulting mixture in this region varies from 415 to $379 \mathrm{~K}$ and is determined by a relatively low amount of hot IEGR and a relatively high amount of cold fresh air-fuel charge. The existence of a relatively high temperature gradient (from 415 to $379 \mathrm{~K}$ ) for the $\varphi_{\mathrm{EC}}$ from 275 to $315^{\circ} \mathrm{CA}$ and the $\varphi_{\text {IO }}$ from 405 to $485^{\circ} \mathrm{CA}$ is mainly due to the influence of temperature variations in IEGR (caused during the compression process of IEGR in the exhaust stroke) and less due to the influence of reverse IEGR flow (at the intake valve). On the other hand, a relatively small temperature gradient (from 403 to $379 \mathrm{~K}$ ) for the $\varphi_{\mathrm{EC}}$ from 245 to $275^{\circ} \mathrm{CA}$ and the $\varphi_{\text {IO }}$ from 405 to $445^{\circ} \mathrm{CA}$ is probably due to the larger influence of the reverse flow than that of the temperature variations in IEGR.

A relatively low mixture temperature and small IEGR quantity in the third region may cause mixture autoignition not to occur and require a spark plug to be used to initiate the autoignition. The dilution of the resulting charge and the temperature rise from the spark ignition combustion will be high enough to trigger the autoignition in the remaining unburned mixture and to sustain CAI combustion in the way explained in section 6 .

\subsection{Influence of the $\mathrm{EO}$ and $\mathrm{IC}$ valve timings on engine parameters and charge properties}

From the test results obtained using the single-cylinder research engine equipped with the FVVT system (explained in section 3 ) and from the experiments per- formed by Koopmans and Denbratt $[\mathbf{8}]$ it was found that $\varphi_{\text {EO }}$ and $\varphi_{\text {IC }}$ have a minor influence on the gas exchange process in a CAI engine. The $\varphi_{\mathrm{EO}}$ has the major influence on pressure waves generated by the blowdown and displacement processes. This result is in agreement with the test results reported in reference [9]. Nevertheless, the pressure waves may have an influence on the IEGR quantity trapped at the EC point, but this influence is negligible in comparison with the influence of the $\varphi_{\mathrm{IO}}$ and $\varphi_{\mathrm{EC}}[19]$.

The $\varphi_{\text {IC }}$ has a very low impact on the engine parameters as it mainly influences the effective displacement volume and effective compression ratio. This result is also in agreement with the test results reported in reference [9].

\section{CONCLUSIONS}

The influence of the variable valve timing strategy on the gas exchange process in a CAI engine fuelled with standard gasoline fuel (95RON) has been analysed. The analysis was performed by the experimental and modelling approach. A single-cylinder research engine equipped with a fully variable valvetrain (FVVT) system was used for the experimental study. A combined code consisting of a detailed chemical kinetics code and one-dimensional fluid dynamics code was used for the modelling study.

The results obtained indicate that the variable valve timing strategy has a strong influence on the gas exchange process, which in turn has a significant effect on the engine parameters and charge properties and hence on the CAI combustion. The $\varphi_{\mathrm{EC}}$ has the strongest influence, followed by the $\varphi_{\mathrm{IO}}$, while $\varphi_{\mathrm{EO}}$ and $\varphi_{\mathrm{IC}}$ have a minor influence.

The $\varphi_{\mathrm{EC}}$ primarily determines the IEGR quantity and consequently the amount of fresh charge and therefore influences the engine load, indicated power and volumetric efficiency. Furthermore, the IEGR quantity (the $\varphi_{\mathrm{EC}}$ ) affects the charge mixture composition, temperature and pressure at the IC point and therefore the autoignition timing and further combustion process, and hence the control of the CAI combustion.

The influence of $\varphi_{\mathrm{IO}}$ on engine parameters and control of CAI combustion is less pronounced. The $\varphi_{\mathrm{IO}}$ mainly influences the pumping losses and reverse flow of the IEGR at the intake valve.

The influence of $\varphi_{\mathrm{EO}}$ and $\varphi_{\mathrm{IC}}$ on the engine parameters and charge mixture properties is negligible.

It can be concluded that the use of the variable valve timing strategy has the potential to control the engine parameters and charge properties at the IC point, and hence CAI combustion.

Along with the gas exchange process, the mixing process that takes place between the IO event and the IC 
event may influence the engine parameters and charge properties. The mixing process will be studied in future research, and the results will be published elsewhere.

\section{REFERENCES}

1 Onishi, S., Jo, S. H., Shoda, K., Jo, P. D. and Kato, S. Thermo-atmosphere combustion (ATAC) - a new combustion process for internal combustion engines. SAE paper 790501, 1979.

2 Noguchi, M., Tanaka, Y., Tanaka, T. and Takeuchi, Y. A study on gasoline engine combustion by observation of intermediate reactive products during combustion. SAE paper 790840, 1979.

3 Hultqvist, A., Engdar, U., Johansson, B. and Klingmann, J. Reaction boundary layers in homogeneous charge compression ignition (HCCI) engine. SAE paper 2001-01-1032, 2001.

4 Hultqvist, A., Christensen, M., Johansson, B., Richter, M., Nygren, J., Hult, J. and Alden, M. The HCCI combustion process in a single cycle-high fuel tracer LIF and chemiluminescence imaging. SAE paper 2002-01-0424, 2002.

5 Milovanovic, $\mathbf{N}$. and Chen, R. A review of experimental and simulation studies on controlled auto-ignition combustion. SAE paper 2001-01-1890, 2001.

6 Law, D., Kemp, D., Allen, J., Kirkpartick, G. and Copland, T. Controlled combustion in an IC-engine with a fully variable valve train. SAE paper 2000-01-0251, 2000.

7 Turner, J., Blundell, D., Bassett, M., Pearson, R. and Chen, R. The impact on engine performance of controlled auto ignition versus spark ignition with two methods of load control. In Proceedings of GPC 2002 Global Powertrain Congress, Michigan, September 2002.

8 Koopmans, L. and Denbratt, I. A four stroke camless engine, operated in homogeneous charge compression ignition mode with commercial gasoline. SAE paper 2001-01-3610, 2001.

9 Heywood, J. B. Internal Combustion Engine Fundamentals, 1988 (McGraw-Hill Book Company).

10 Kee, R. J., Rupley, F. M., Meeks, E. and Miller, J. A. CHEMKIN III: a Fortran chemical kinetics package for the analysis of gas-phase chemical and plasma kinetics. Report SAND96-8216, Sandia National Laboratories, Livermore, California, 1996.

11 Lotus Engine Simulation (LES) Code Manual, 2001 (Lotus Cars Company Limited, Hethel, Norfolk).

12 Woschini, G. Universally applicable equation for the instantaneous heat transfer coefficient in the internal combustion engine. SAE paper 670931, 1967.

13 Ogink, R. and Golovitchev, V. Gasoline HCCI modeling: computer program combining detailed chemistry and gas exchange process. SAE paper 2001-01-3614, 2001.

14 Westbrook, C. Chemical kinetics of hydrocarbon ignition in practical combustion systems. In Proceedings of 28th Combustion Symposium, Edinburgh, July 2000, Plenary Lecture.

15 Chen, R., Milovanovic, N. and Law, D. A computational study on the ignition timing of HCCI combustion in IC engine fuelled with methane. In Proceedings of 2002 Spring Technical Meeting of the Combustion Institute, Canadian Section, Windsor, Canada, May 2001, paper 53, pp. 158-163 (Canadian Section of The Combustion Institute).

16 Chen, R., Milovanovic, N., Turner, J. and Blundell, D. Thermal effect of internal gas recirculation on controlled auto ignition. SAE paper 2003-01-0750, 2003.

17 Chen, R. and Milovanovic, N. A computational study into the effect of exhaust gas recycling on homogeneous charge compression ignition combustion in internal combustion engine fuelled with methane. Int. J. Thermal Sci., 2002, 41, 805-813.

18 Milovanovic, N., Chen, R., Law, D. and Turner, J. Homogeneous charge compression ignition combustion and fuel composition. In Proceeding of 17 th Internal Combustion Engine Symposium, Tokyo, October 2002, paper 20026075, pp. 361-364 (JSAE).

19 Koopmans, L., Backlund, O. and Denbratt, I. Cycle to cycle variations: their influence on cycle resolved gas temperature and unburned hydrocarbons from a camless gasoline compression ignition engine. SAE paper 2002-91-0110, 2002

20 Koopmans, L., Ström, H., Lundgren, S., Backlund, O. and Denbratt, I. Demonstrating a SI-HCCI-SI mode change on a Volvo 5-cylinder electronic valve control engine. SAE paper 2003-01-0753, 2003.

21 Zhao, H., Li, J., Ma, T. and Ladommatos, N. Performance and analysis of a 4-stroke multi-cylinder gasoline engine with CAI combustion. SAE paper 2002-01-0420, 2002. 